\title{
Equity in new active travel infrastructure: A spatial analysis of London's new Low Traffic Neighbourhoods
}

\author{
Rachel Aldred ${ }^{\mathrm{a}, *}$, Ersilia Verlinghieri ${ }^{\mathrm{a}}$, Megan Sharkey ${ }^{\mathrm{a}}$, Irena Itova ${ }^{\mathrm{a}}$, Anna Goodman ${ }^{\mathrm{b}}$ \\ ${ }^{\text {a }}$ University of Westminster, UK \\ ${ }^{\mathrm{b}}$ London School of Hygiene and Tropical Medicine, UK
}

\section{A R T I C L E I N F O}

\section{Keywords:}

Transport equity

Active travel infrastructure

Low traffic neighbourhood

London

\begin{abstract}
A B S T R A C T
In this article we examine equity in new active travel infrastructure in London, UK. We focus on Low Traffic Neighbourhoods (LTNs) introduced during Covid-19. These area-based schemes mainly involve 'modal filters' that restrict through motor traffic from residential streets within a neighbourhood. Such approaches to traffic management are traditional in the Netherlands, but are relatively novel in London and other global cities such as Barcelona. LTNs are often controversial, with one criticism being that they are implemented in affluent areas and hence benefit richer residents.

London represents an excellent opportunity to investigate whether these rapidly introduced schemes have so far been equitably distributed. We focused on LTNs introduced between March and September 2020 and still present at the end of October 2020. Having generated datasets representing these new LTN locations and their boundary roads, we matched these to Output Areas (OAs, administrative areas containing around 300 residents). We then examined the extent to which LTN implementation was associated with age, ethnicity, disability, employment and car ownership (using Census 2011 data) and small-area deprivation (using the Index of Multiple Deprivation 2019).

We estimated that $3.7 \%$ of all Londoners live inside a new LTN, and $8.9 \%$ live within $500 \mathrm{~m}$ walking distance of a new modal filter. Across London as a whole, people in the most deprived quarter of OAs were 2.5 times more likely to live in a new LTN, compared to Londoners in the least deprived quarter. While overall Black, Asian and Minority Ethnic (BAME) people were slightly more likely than White Londoners to live in a new LTN, this varied by ethnic group. Specifically, Black Londoners were somewhat more likely, and Asian Londoners somewhat less likely than White people to live in a new LTN. Car-free households were more likely to live in a new LTN.

We also examined equity within London's districts, which lead on implementation of LTNs. In the median district, people in more deprived areas were more likely to live in an LTN than people in less deprived areas, suggesting that, on average, individual districts have prioritised their more deprived areas. However, in the median district, BAME residents were slightly less likely to live in an LTN than White residents. Across districts implementing LTNs there was wide variation, with some much more or less equitable than others. A third of districts implemented no LTNs at all. Finally, at the micro level, residents living in LTNs were demographically similar to neighbours living in OAs that touched an LTN boundary road.

We conclude that LTN implementation has been broadly equitable at the city and micro levels, but the picture is more mixed at the district level, despite districts being encouraged to consider deprivation when planning LTN locations. Equity metrics should be used in policy and research to monitor and improve the distribution of active travel interventions.
\end{abstract}

\section{Introduction}

Many cities and countries, including London and the UK, have ambitions to build walking and/or cycling (active travel) infrastructure to reduce air pollution and carbon emissions, and increase physical activity. With the Covid-19 pandemic, addressing such issues, and

\footnotetext{
* Corresponding author at: School of Architecture and Cities, Westminster University, 35 Marylebone Road, NW1 5LS, UK.

E-mail addresses: r.aldred@westminster.ac.uk (R. Aldred), e.verlinghieri@westminster.ac.uk (E. Verlinghieri), M.Sharkey@my.westminster.ac.uk (M. Sharkey), I. Itova1@westminster.ac.uk (I. Itova), anna.goodman@lshtm.ac.uk (A. Goodman).
} 
providing space for physical distancing, became an urgent necessity (Connolly, 2020; Dunning and Nurse, 2020). With residents unwilling or unable to use public transport (Papa and Badstuber, 2020), appropriate active travel infrastructure became a priority. However, both in London and other contexts, this infrastructure was often absent or, when present, of poor quality and/or not equitably distributed. For example, London cycle superhighways have specifically targeted those commuting to the city centre, which may exclude some trip purposes and some demographics less likely to commute, or less likely to commute to central business districts.

Equity in active travel infrastructure provision is, however, generally under-researched including, at this point, for interventions introduced in response to Covid-19. One exception is a recent paper from North America finding that 'slow streets' interventions in Seattle and Vancouver were more likely to be introduced in areas where Black and Indigenous people live (Firth et al., 2021). This paper examines the implementation of 'Low Traffic Neighbourhoods' (LTNs) across London between March and September 2020, through the introduction of 'modal filters'. ${ }^{1}$ We examine the provision of these new LTNs at the small area level, in relation to demographic indicators, including ethnicity, area deprivation and disability.

\section{Equity and active travel environments}

Equity is increasingly a concern of transport planners and researchers, with key studies highlighting the societal cost of unequal access to transport in terms of health disparities, social deprivation, social exclusion and poverty (Lucas, 2012; Lucas et al., 2016; Lucas and Jones, 2012). Research has shown how negative impacts of motorised transport are usually unevenly distributed, with vulnerable communities disproportionately affected by transport-related air pollution (Barnes et al., 2019; Fecht et al., 2015; Jephcote et al., 2016) or climate change (Walker and Burningham, 2011).

Less is known about the distribution across different population groups of access to active travel interventions (Braun et al., 2019) - i.e. a transport 'good' that can promote health by increasing physical activity (Woodcock et al., 2013; Rabl and de Nazelle, 2012). Here we examine (in)equality in the provision of LTNs, a type of area-level active travel infrastructure which may have substantial potential to improve conditions for walking and cycling (Aldred and Goodman, 2020). Ensuring equitable access is vital for increasing uptake of healthy mobility among people often with fewer other options (e.g. more likely to be living without a car). Providing a better environment for existing low-income walkers or cyclists is also important: these may be 'no-choice' active travellers (Bostock, 2001) forced to walk or cycle in relatively risky environments (Aldred, 2018).

So far, the use of spatial analysis to explore the distribution of active travel infrastructure mostly covers North or Latin America, and predominantly cycling rather than walking infrastructure. Studies often find inequitable distribution, with lower access to cycling infrastructure in more deprived areas (e.g. Braun et al., 2019; Flanagan et al., 2016; Hirsch et al., 2017; Parra et al., 2018; Teunissen et al., 2015; Tucker and Manaugh, 2018); although this is not always the case (Pistoll and Goodman, 2014; Houde et al., 2018). Equity analyses of pedestrian infrastructure or walkability have more mixed results. These mixed findings may partly reflect greater variation between studies in how walkability is defined (e.g. 'presence of a footway' is used as an indicator in North American studies, but would be taken for granted in Northern European cities). It also reflects variation between cities and countries in

\footnotetext{
${ }^{1}$ A 'modal filter' is a bollard, camera gate, planter, or other street feature that restricts motor traffic fully or partially (the latter might involve a cameracontrolled bus gate, or other specific exemptions such as local refuse vehicles). They are intended to reduce through motor traffic on a neighbourhood's streets.
}

the historical and contextual factors that have shaped the relationship between pedestrian resources and household disadvantage (Macintyre et al., 2008).

Thus, a systematic review by Jacobs et al. (2019) shows a varied picture across Western countries. They found that higher deprivation was associated with reduced access to green space. Beyond this, there was no clear association between socioeconomic factors and presence of walking infrastructure across countries, but overall slightly more positive than negative associations between deprivation and walkability. A North American study (Thornton et al., 2016) found that the association of microscale walkability features with diversity and deprivation varied: more diverse and deprived areas tended to have more crossings and footways, but poorer aesthetic characteristics and more signs of disrepair such as litter or broken glass. A recent study of eight capital cities across Europe (Bartzokas-Tsiompras et al., 2020) found that the highest quality pedestrian environments were in affluent central areas, with far lower quality environments in surrounding more deprived areas.

Many of the UK studies that cover walkability focus on access to parks and greenspace, and mirror the international literature in finding lower access in more deprived areas (Mitchell and Popham, 2008; Wheeler et al., 2015; Ferguson et al., 2018; Mears et al., 2019). One study that looked at walkability more widely is Kenyon and Pearce's (2019) analysis of walkability in Glasgow and Edinburgh. The authors measured walkability by combining residential density, intersection density and destination accessibility. They found that walkability is generally worse for people living in more affluent areas, with lower densities being the determining factor. This was also found in a study by Zandieh et al. (2017) in Birmingham. The analysis does not, however, include aspects related to the aesthetics, quality or safety of the walking environments, potentially crucial for walking uptake (Adkins et al., 2017) as well as enjoyment.

In summary, access to cycling infrastructure is often (though not always) lower in more deprived areas. Definitions of walkability based on accessibility or density tend to suggest a relatively fair distribution of walking environments, but this appears less the case when including indicators of pedestrian environment quality, such as aesthetics or presence of greening. In addition, lower income groups and ethnic minorities are consistently found to have lower access to private and public green spaces. Hence, active travel infrastructure that increases the environmental quality of neighbourhood streets may be particularly important for these groups.

Within the literature on pedestrian environment quality, there is an important gap related to levels of motor traffic. This goes beyond whether a street is designated 'major' or 'minor'. Hart and Parkhurst (2011), repeating Donald Appleyard's (1969) classic study, found substantial differences in sociability and quality of life for people living on an urban residential street without through motor traffic, compared to one carrying substantial through traffic. The impact of reducing motor traffic on local streets can be profound and fast: LTN measures, introduced between 2015 and 2019 in the district of Waltham Forest, increased active travel within a year, particularly walking, and within two years reduced car use and/or ownership (Aldred and Goodman, 2020; Goodman et al., 2020). This suggests that LTN implementation may improve the convenience of walking or cycling and/or improve environmental quality. Such changes could substantially contribute to creating more equitable urban spaces if implemented in more deprived areas where residents lack private greenspace, yet conversely could aggravate gaps if concentrated in affluent areas.

\section{Case study: London}

Within London, there is substantial variation in the quantity and quality of transport provision, including active travel infrastructure, and, relatedly, in travel behaviour. Analyses of walkability in terms of residential dwelling density, street connectivity and land use mix show a clear radial decay in the index from centre to periphery (Stockton et al., 
2016). Although walking levels are high relative to the rest of the UK and many other European cities, there is scope for further growth and shifting short trips away from car use. This is reflected in the city-wide goal that $80 \%$ of trips be made by walking, cycling, or public transport by 2041 , compared to $63 \%$ today (Transport for London, 2018).

London's Mayor oversees the regional transport authority, Transport for London (TfL). TfL controls around 5\% of the capital's roads, including many primary (A) class roads. The remaining $95 \%$ of roads are under the control of London's 33 districts. Hence, interventions on residential streets, such as LTNs, tend to be led by districts, even if funded by TfL. However, TfL does play a role, including through issuing guidance and deciding upon funding applications. In Appendix A we provide more information on how this process worked in the case of recent LTNs, and criteria by which TfL suggested districts should identify intervention sites.

Across London, around $90 \%$ of people live on residential streets (typically minor 'unclassified' streets, which are not main roads, high streets, or industrial zones), and this figure is similar across a range of demographic groups (Aldred and Verlinghieri, 2020). Data suggests that London's minor roads have seen an increase of $72 \%$ in motor traffic over the past decade, while traffic on its major roads fell by 3\% (DfT, 2020). This has provided an additional argument for LTNs, introduced at pace during the 2020 Covid-19 outbreak in the UK capital through emergency provisions allowing expedited implementation with concurrent consultation. Whereas North American 'slow streets' have been characterised and analysed as street-level interventions (Firth et al., 2021), LTNs are designed to be area-level, covering a number of contiguous residential streets within a neighbourhood.

By restricting motor traffic volumes on residential streets using modal filters (Fig. 1), LTNs can create streets where pedestrians may use more of the carriageway, and space is freed up to install parklets, benches, and other street furniture. During the Covid-19 pandemic, LTNs have specifically been used to provide more physical distancing space, especially with a rise in jogging and running on sometimes narrow footways. If perceived to be successful they may be made permanent, and more introduced, aiming to avert a car-based recovery which would place stress on local roads and could further worsen air quality.

Despite evidence of benefits, active travel interventions remain highly controversial in the UK. Cycle tracks have long been the subject of complaint, legal action, and even sabotage in London and the UK, and more recently, the same has been true of LTNs (e.g. see Edwards, 2020). As well as opposition referencing the right to drive, some resistance to LTNs has been framed through an equity/environmental/health lens.

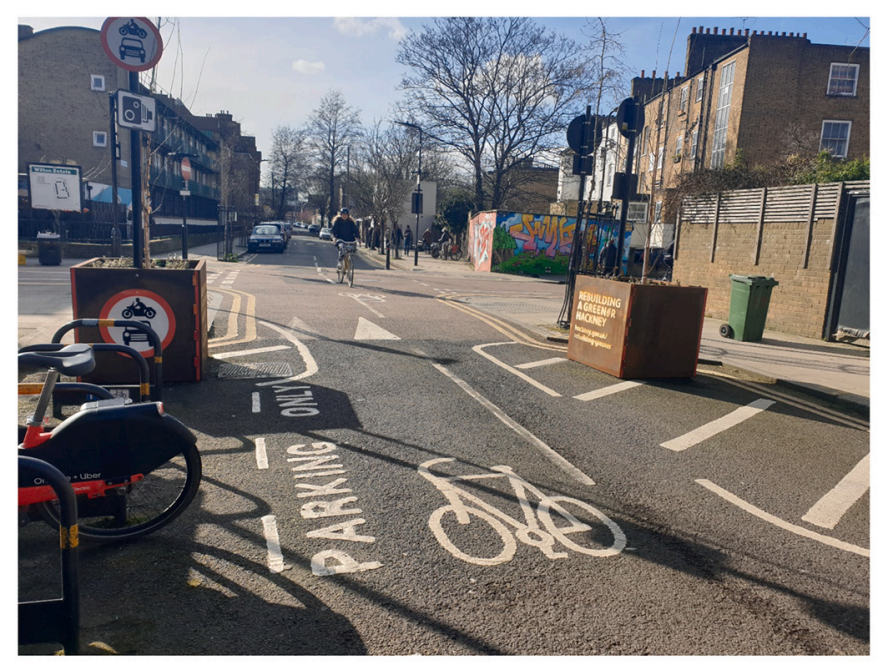

Fig. 1. Modal filter in Hackney, East London (sign with red border indicates 'no motor traffic'. Those in private cars can drive up to the filter on each side but not pass through it).
For instance, LTNs have been characterised as being predominantly implemented in affluent parts of London and/or, at a more micro level, of unfairly diverting motor traffic from affluent residential streets inside the LTN to poorer and more ethnically diverse boundary roads and areas. Our paper responds to this debate by examining the extent to which LTNs have been distributed in an equitable manner, or whether they have been concentrated in particular types of area within the city or within districts.

\section{Methodological approach}

\subsection{Research questions}

This study uses a spatial equity approach to examine where new LTNs have been implemented in London between March 2020 (when the first Covid-19 lockdown started) to September 2020 (the time when this research project started).

Our analysis addressed the following research questions:

1. With respect to key dimensions of equity (e.g. ethnicity, deprivation), how equitably are LTNs distributed across London? For example, how likely are White Londoners to live in a new LTN, compared to Black, Asian or Minority Ethnic Londoners?

2. Are there differences between LTNs and nearby surrounding areas in relation to the dimensions of equity addressed in (1)?

3. Are any relationships (or lack thereof) observed for London as a whole in (1) also present within individual districts? For instance, if people living in more deprived areas across London as a whole are disproportionately likely to have received a new LTN, does this also hold true within districts; or does the observed London-wide relationship stem from more deprived districts having been more likely to introduce LTNs?

We include the second research question because nearby areas might experience at least short-term traffic displacement after introducing a new LTN. In addition, while LTNs can benefit people living in nearby areas through increased opportunities to make local trips by foot or by bicycle, the magnitude of this benefit is expected to be even greater for residents living inside an LTN, who also enjoy the benefits of reduced motor traffic in the street that they live on. As such, differences in demographic characteristics between LTN areas and nearby areas might indicate an equity issue, even without any sustained disbenefit to nearby areas.

The third research question is important because $95 \%$ of London's roads are controlled by its 33 districts rather than by its regional transport authority, and therefore districts are responsible for deciding whether, where, and how LTNs are implemented. ${ }^{2}$ Hence it is crucial to examine how equitably individual districts are pursuing LTN policies, as well as examining the picture across London as a whole.

\subsection{Identifying new modal filters and LTNs}

We compiled a dataset of modal filters, LTN areas and associated boundary roads, covering measures implemented between March-September 2020 and still in place by the end of October $20202 .{ }^{3}$ There was no official spatial dataset for London of the location and installation date of new modal filters nor of LTN boundaries. Therefore, we compiled this information ourselves using district websites; the Transport for

\footnotetext{
${ }^{2}$ However, note that this will depend on funding, which in the case of these interventions mostly came via Transport for London.

${ }^{3}$ With a constantly changing implementation picture, some cut-off was needed, and March-September covered many (though not all) schemes funded in the first wave of funding.
} 
London website ${ }^{4}$; and the Gazette, ${ }^{5}$ the official record of traffic orders. We contacted district officers, councillors, and/or civil society groups in all 33 districts to check our maps and/or source additional information. This was an iterative process following which we shared a draft map on social media from October $20205^{6}$ and obtained further comments, including from residents supporting or opposing schemes. This process led us to double-check modal filter locations and boundaries, adjusting as necessary. The scrutiny from interested members of the public as well as stakeholders was helpful in improving the accuracy of our dataset, and has provided useful information for those groups in debating issues around LTNs.

An early issue we faced was defining a 'modal filter'. The term implies that some transport modes are 'filtered' out; however, no unique definition exists across London districts and we had to consider whether, for instance, we should include filters with substantial exemptions for some motor traffic or those that operated highly restricted hours. Our final definition includes physical filters, e.g. planters or lockable bollards; bus gates, which use Automatic Number Plate Recognition cameras to restrict motor traffic other than buses; and camera filters that were only operational for parts of the day but that did restrict traffic for at least five hours. We did not include 'School Streets' where filters only operate during school opening and closing times (around $3 \mathrm{~h}$ per day in total). We considered whether to include the motor-vehicle restrictions in the district of Hammersmith and Fulham. These exempt all district residents, even those living outside of the LTN, which substantially reduces the likely decline in motor traffic flow. While we feel that this is probably not within the spirit of an LTN, we have left it in for this analysis since it was introduced as part of the same programme of Covid19 transport interventions that included our other LTNs.

Having defined modal filters, identifying their location was in principle straightforward once information was gathered. Defining the boundaries of LTNs was more difficult. ${ }^{7}$ First, there was the question as to whether new modal filters meant that a new LTN had been created or not. In some cases, one or two modal filters had been installed that did not appear to have an area-wide effect. For example, there were several examples in South London of isolated modal filters being used to create a quiet street next to a primary school - i.e. a permanent 'School Street' but not a more comprehensive LTN. Similarly, in Central London several examples affected a small standalone section of a shopping street. Hence, in a few cases, there were no LTNs corresponding to a modal filter or pair of filters, although we are still able to look at such areas through our modal filter proximity analysis. A total of 34 out of the 411 new modal filters were not, in our view, part of a new LTN.

We defined the boundaries of LTNs specifically for the purpose of this paper and hence not necessarily in line with areas shown in intervention maps drawn by districts. For this analysis, a 'new LTN' is that area in which we would expect the new modal filters installed between March and September 2020 to have reduced through motor traffic. By contrast, some districts included a wider area within an official LTN map, for instance a larger new zone with reduced speed limits only, or an adjacent area already impermeable to through motor traffic. We also removed roads continuing to carry substantial through motor traffic from our spatial dataset of the extent of LTNs, and trimmed the LTN

\footnotetext{
${ }^{4}$ https://data.london.gov.uk/dataset/cycling-infrastructure-database

5 https://www.thegazette.co.uk/

6 https://www.google.com/maps/d/u/0/viewer? mid=1m_ZQHAQOWGRu7-IZDP-gbV8Mr6ZfMOj

${ }^{7}$ Note also that not all districts described these interventions as 'LTNs'.
}

areas to exclude buildings facing onto those roads. We generated a separate set of what we called 'LTN boundary roads 8 , for analysis of differences between those living inside LTNs versus those living in nearby boundary areas. An example of the spatial data is shown in Fig. 2.

We learnt through this process that there is inevitably some subjectivity involved in defining LTN boundaries using this approach. Future research could explore other approaches to identifying such boundaries, for instance using spatial analysis of (changes in) motor vehicle connectivity to identify LTN-type areas. At present, an iterative manual process involving input from councillors, officers, and residents, sharing of our drafts online, and subsequent discussion and amendment is the best that we were able to achieve.

Finally, we note that our research effort focused only on identifying new LTNs. We did not attempt to identify existing LTNs, which are not widespread in London but do exist in at least some districts (e.g. the district of Hackney introduced several such schemes in the 1970s). However, there exists no dataset - e.g. a dataset of existing modal filters across London - that would make it feasible for us to identify all such schemes.

\subsection{Small-area demographic and social-economic information}

The Greater London Authority is comprised of 25,053 Output Area (OAs), these being administrative areas containing around 300 people. The 2011 Census provided the number of individuals and households in each OA, plus information on age, ethnicity and disability for individuals, and on employment status and car/van availability for households. We also matched each OA to its 2019 overall deprivation rank from the Index of Multiple Deprivation, which is calculated at the Lower Super Output Area level (LSOA: there are around 5 OA per LSOA).

Unfortunately, the most recent UK Census data is 10 years old. More recent data on registered motor vehicles is available at the LSOA level from the Driver and Vehicle Licensing Agency. At the LSOA level, we found a 0.91 correlation between the proportion of households with a car in 2011 from Census data and the number of cars per capita in 2019 from DVLA data. This correlation was very similar between the 4659 London LSOAs $<50 \%$ inside an LTN $(r=0.91)$ and the $176 \geq 50 \%$ inside an LTN $(r=0.93)$. This provides reassurance that the Census data continues to provide a reasonable reflection of small-area car ownership in London. Note that in our analyses we prefer the older Census data to the DVLA data because the Census (a) is available at finer geographical resolution (OA not LSOA) and (b) provides a measure of car ownership at the household level, as opposed to just the total number of cars registered in an area.

We also compared the most recent 2019 version of the Index of Multiple Deprivation measure with the previous release in 2015. The 2015 release was largely created based on indicators collected in 2011-2012, i.e. from around the same time as the 2011 Census. We compared these two versions of the Index of Multiple Deprivation at the LSOA level using national rankings on the total deprivation score, where ' 1 ' corresponds to the most deprived LSOA in England. The correlation of these two measures was 0.98 . The average change in deprivation rank between 2015 and 2019 was +1130 for LSOAs $<50 \%$ inside an LTN and +1188 for LSOAs $\geq 50 \%$ inside an $\operatorname{LTN}$ ( $p=0.66$ for difference). Thus, there is no evidence that deprivation levels have been changing at a different rate since 2011 in areas that received LTNs versus the rest of London. This provides some further indirect support for the validity of making comparisons using Census 2011 data.

\footnotetext{
${ }^{8}$ We defined boundary roads as those that might plausibly see re-routed traffic from cars unable to pass through the LTN: in most cases these were simply the adjacent roads bounding an LTN (hence the name). However in some cases boundary roads were further away: for instance, where infrastructure such as parks or rail lines lay in-between, or one-way systems on main roads meant alternative routes were further away.
} 


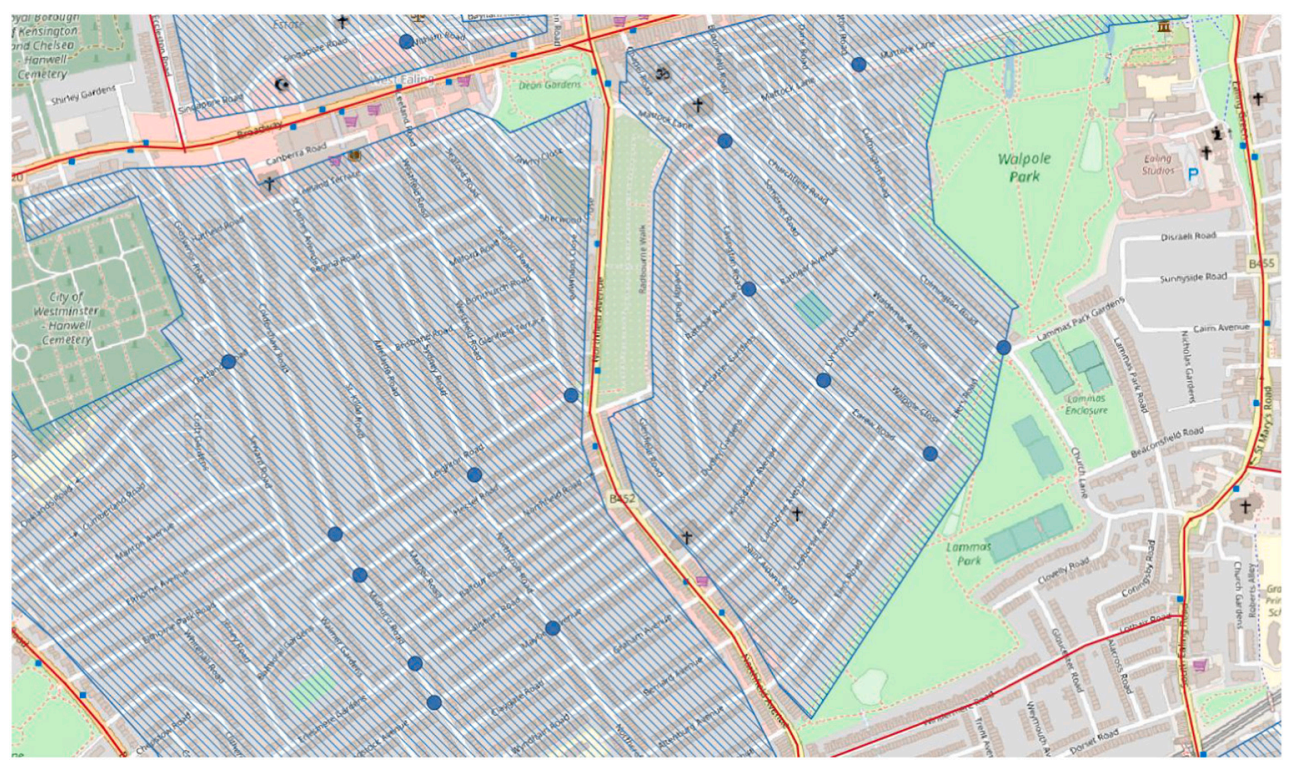

Fig. 2. West London, showing modal filters (dots), LTN areas (hashed), and boundary roads (red). (For interpretation of the references to colour in this figure legend, the reader is referred to the web version of this article.)

\subsection{Defining LTN provision}

Our primary measure of being provisioned with new active travel infrastructure was living inside an LTN. To operationalise this in terms of OA geography, we first calculated the proportion of buildings in each OA that lay inside a new LTN, using Ordnance Survey data on building boundaries. For each characteristic, in turn, we then multiplied the total OA population by the proportion of the OA's buildings inside the LTN. For example, if an OA contained 50 Black residents in total, and $80 \%$ of the building area within that OA lay inside the LTN, the estimated number of Black residents inside the LTN would be $50 * 0.8=40$. This analysis, therefore, used buildings as a proxy for population within an $\mathrm{OA}$ and assumed that demographic and socioeconomic characteristics were evenly distributed across building areas within OAs. To check the impact of these assumptions, we carried out a sensitivity analysis focusing only on OAs 100\% inside an LTN (which would not be affected by the assumptions), finding a near-identical distribution of demographic and socioeconomic characteristics.

Our secondary measure was living within $500 \mathrm{~m}$ of a new modal filter. This has the advantage of being more objective than our attempt to define LTN areas, and also includes people living near the 34 modal filters not part of an LTN. It is, however, a measure of proximity to interventions rather than of direct experience of living within an intervention area. For this measure, we calculated the route-based walking distance from the population-weighted centroid of each $\mathrm{OA}$ to the nearest modal filter using the routing service Graphhopper (graphh opper.com). We included $100 \%$ of residents of any OA that had a route-based walking distance $\leq 500 \mathrm{~m}$ between the centroid and a new modal filter. While any cut-off is somewhat arbitrary, $500 \mathrm{~m}$ is commonly used in literature as a walkable route network distance (e.g. Su et al., 2013).

For our second research question, we compared the characteristics of individuals living fully inside LTNs with the characteristics of neighbours in nearby areas that we considered might be affected by traffic displacement. Specifically, we compared individuals living in OAs $100 \%$ inside an LTN with individuals living in OAs that were $0 \%$ inside an LTN but that touched an LTN boundary road (with 'touching' defined using QGIS Vector Tools). Note that these nearby areas include people living on the boundary roads themselves, but also those living in neighbouring residential streets: this is a limitation of our use of area-level data as we are unable to fully isolate effects on residents of boundary roads only. It does mean that even where there is traffic displacement, it may not directly affect all or even most of those living in an OA touching a boundary road.

\subsection{Data analysis}

For our first and second research questions we present results broken down into multiple demographic and socioeconomic characteristics. For our third, district-level research question we focus on binary comparisons by ethnicity (White versus Black, Asian, and Minority Ethnic, or BAME), disability (any versus none), and area deprivation (50\% most deprived versus $50 \%$ least deprived). We chose these three binary comparisons a priori as reflecting dimensions of equity that have featured most prominently in the debate around LTNs and which are traditionally used in spatial equity analyses. This use of binary comparisons allowed us to generate summary measures of equity according to these three dimensions within districts - for example, in a given district, comparing the proportion of White people provisioned with new infrastructure to the proportion of BAME people.

Because we are using total population data, extremely small differences are statistically significant (e.g. in our London-wide results, all the differences of less than $0.1 \%$ are significant at $p<0.001$, while even at a district level all the differences we found between groups of $0.1 \%$ or higher were significant to $p<0.05$ ). We therefore focus on examining whether the data shows what we see to be meaningful differences, such as an absolute difference of more than 2 percentage points, rather than reporting only the statistical significance. This is analogous to the distinction often made in medical research between statistical significance and clinical significance/effect size.

\section{Results}

\subsection{LTN development by district}

We found that 72 LTNs were implemented between March 2020 and September 2020 across London's 33 districts, involving the placement of 377 new modal filters. Fig. 3 illustrates the pattern of LTN development by districts in London. The extent of new LTNs implemented was highly unequal across districts, with some districts (e.g. Hackney, Islington, Lambeth, Ealing) delivering many schemes during this period, whereas a third of districts built little or nothing. More detail can be found in 


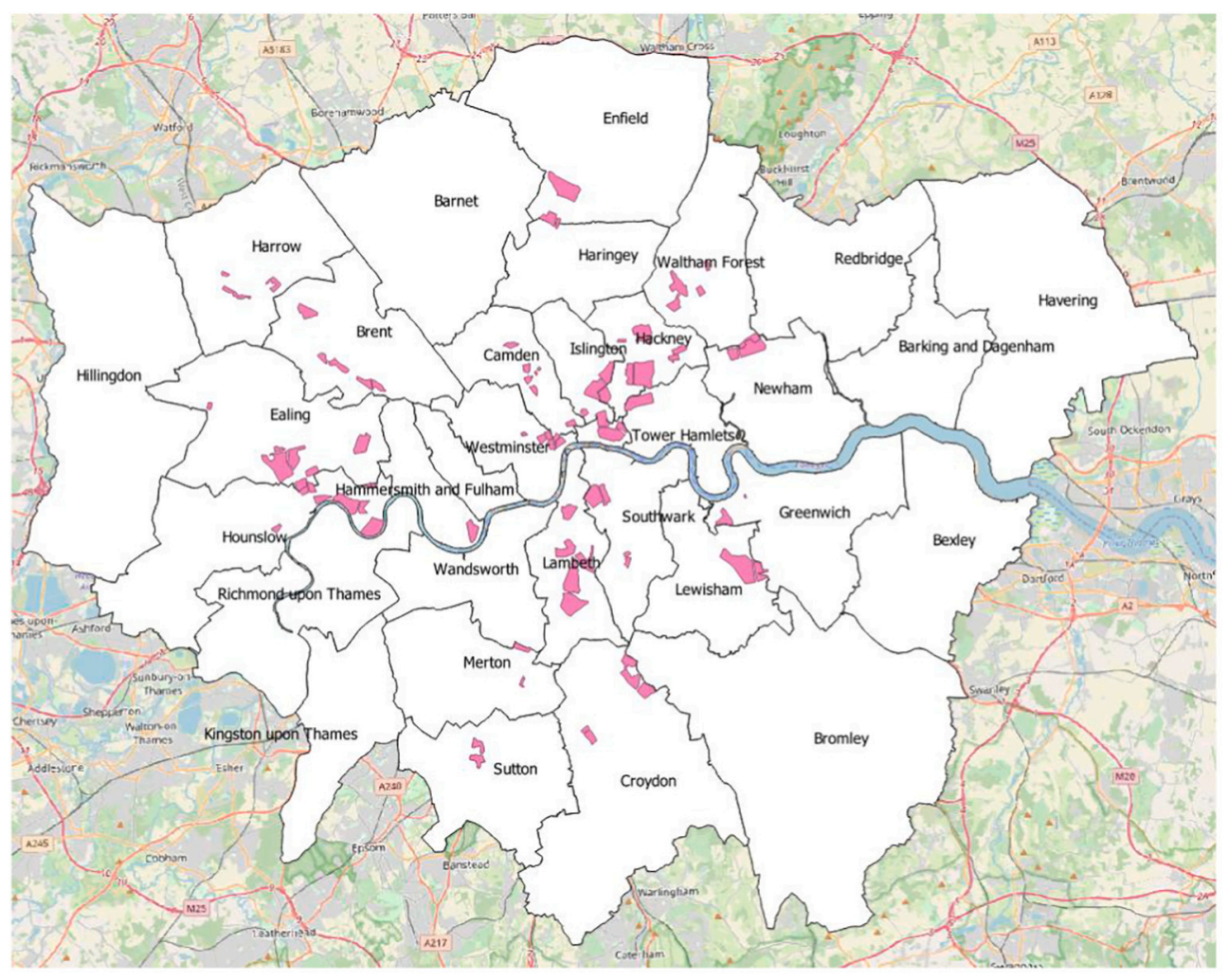

Fig. 3. LTNs across London districts, implemented March-September 2020.

Appendix A.

\subsection{How are different demographic and socioeconomic characteristics associated with the probability of being in an LTN?}

Table 1 presents the results at a London-wide level. We estimate that as of October 2020, 3.7\% of Londoners lived inside a new LTN and 8.9\% Londoners lived within $500 \mathrm{~m}$ of any new modal filter.

The most pronounced demographic or socio-economic difference observed was related to deprivation. 5.1\% of Londoners living in the $25 \%$ most deprived OAs lived in a new LTN, whereas this was true for only $2.0 \%$ of those living in the $25 \%$ least deprived OAs. In addition, $3.1 \%$ of people in car-owning households were inside a new LTN compared to $5.0 \%$ of people living in households without a car.

With respect to age, children and elderly people were slightly less likely to live in LTNs. In addition, Asian Londoners were less likely to live in a new LTN than White Londoners (2.9\% vs 3.6\%), whereas Black Londoners and people of Mixed or Other ethnicity were more likely to live in an LTN (5.0\% and 4.1\%, respectively). Overall, 3.6\% of White and $3.9 \%$ of BAME Londoners lived in a new LTN. There was very little difference by employment status or disability status. See Appendix Table A2 for a version of Table 1 using column instead of row percentages.

This pattern of findings was almost identical in a sensitivity analysis focusing on the $1.8 \%$ of residents living inside OAs that were $100 \%$ within the boundaries of an LTN (Appendix B). The results shown in Table 1 were also generally similar in analyses stratified between Inner and Outer London, except that Outer London showed smaller differences by ethnicity and deprivation (Appendix B). Appendix B presents the equivalent to Table 1 for individual districts.

\subsection{Comparison of LTN residents with their neighbours in nearby areas}

Table 2 compares the characteristics of people living fully inside
LTNs with people living in non-LTN areas that touch LTN boundary roads. We present this table differently from Table 1 (using now column percentages in place of row percentages) because here the focus is not on comparing people with different characteristics (e.g. what percentage of White versus Black Londoners live in an LTN) but comparing different areas (e.g. what is the ethnic composition of OAs fully within LTNs versus nearby areas outside them). As discussed above, people in those nearby areas might or might not experience benefits (e.g. due to access to quieter walking and cycling routes) and/or disbenefits (e.g. due to displaced motor traffic) from the LTNs; but are unlikely to benefit as much as people living in areas wholly within an LTN.

As presented in Table 1 above, demographic and socioeconomic differences were generally modest. The proportion of children and older adults was slightly higher inside LTNs than in nearby boundary areas, as was the proportion of disabled Londoners, Black Londoners, and households with no employed adults. The reverse was true for Asian Londoners and households with no car. There was no clear trend in area deprivation at this micro-level, with a slightly higher proportion of both the most and the least deprived quarters living inside LTNs than in nearby areas.

All these differences were relatively small in absolute terms, with differences $>2 \%$ observed only with respect to Asian ethnicity (Asian Londoners comprising a somewhat smaller proportion in LTNs than in nearby areas) and some deprivation categories (individuals in the most and least deprived quarters comprising a somewhat larger proportion in LTNs than in nearby areas). Our findings with respect to deprivation were almost identical in a sensitivity analysis that excluded 46 LSOAs straddling the boundary between LTNs and nearby non-LTN areas (since this could artificially homogenise deprivation levels between the two areas): see Appendix B.

Overall, Table 2 suggests that areas fully inside LTNs are not more advantaged than nearby non-LTN areas. This is reassuring for planners, as it suggests there is not a systematic equity problem in this regard linked to the type of areas that have so far been made into LTNs. 
Table 1

Proportion of Londoners living in and near LTNs, by demographic and socioeconomic characteristics (row percentages).

\begin{tabular}{|c|c|c|c|c|}
\hline & & $\begin{array}{l}\text { Total number } \\
\text { across } \\
\text { London }^{\mathrm{a}}\end{array}$ & $\begin{array}{l}\text { Inside a } \\
\text { new LTN }\end{array}$ & $\begin{array}{l}\text { Within } 500 \mathrm{~m} \\
\text { of a new } \\
\text { modal filter }\end{array}$ \\
\hline All & & $8,173,941$ & $3.7 \%$ & $8.9 \%$ \\
\hline \multirow[t]{4}{*}{ Age } & 0 to 4 & 591,495 & $3.5 \%$ & $8.5 \%$ \\
\hline & 5 to 17 & $1,219,899$ & $3.4 \%$ & $7.8 \%$ \\
\hline & 18 to 64 & $5,457,798$ & $3.9 \%$ & $9.5 \%$ \\
\hline & $65+$ & 904,749 & $3.2 \%$ & $7.2 \%$ \\
\hline \multirow[t]{4}{*}{ Ethnicity } & White & $4,879,239$ & $3.6 \%$ & $8.7 \%$ \\
\hline & Black & $1,088,640$ & $5.0 \%$ & $11.8 \%$ \\
\hline & Asian & $1,511,546$ & $2.9 \%$ & $6.9 \%$ \\
\hline & $\begin{array}{l}\text { Mixed or } \\
\text { other }\end{array}$ & 694,516 & $4.1 \%$ & $10.3 \%$ \\
\hline \multirow[t]{3}{*}{ Disability } & Not disabled & $7,016,776$ & $3.7 \%$ & $9.0 \%$ \\
\hline & $\begin{array}{l}\text { Limited a } \\
\text { little }\end{array}$ & 605,501 & $3.7 \%$ & $8.5 \%$ \\
\hline & Limited a lot & 551,664 & $3.8 \%$ & $8.8 \%$ \\
\hline \multirow{2}{*}{$\begin{array}{l}\text { Household car } \\
\text { ownership }\end{array}$} & None & $1,357,251$ & $5.0 \%$ & $12.6 \%$ \\
\hline & 1 or more cars & $1,908,922$ & $3.1 \%$ & $7.4 \%$ \\
\hline \multirow[t]{2}{*}{$\begin{array}{l}\text { Household } \\
\text { employment }\end{array}$} & $\begin{array}{l}\text { Any employed } \\
\text { adult }\end{array}$ & $2,345,738$ & $3.9 \%$ & $9.7 \%$ \\
\hline & $\begin{array}{l}\text { No employed } \\
\text { adult }\end{array}$ & 920,435 & $3.8 \%$ & $9.2 \%$ \\
\hline \multirow[t]{4}{*}{$\begin{array}{l}\text { Area } \\
\text { deprivation }\end{array}$} & $\begin{array}{l}\text { Quarter } 1 \\
\text { (least } \\
\text { deprived) }\end{array}$ & $1,941,076$ & $2.0 \%$ & $4.9 \%$ \\
\hline & Quarter 2 & $2,040,925$ & $2.6 \%$ & $7.3 \%$ \\
\hline & Quarter 3 & $2,122,020$ & $5.0 \%$ & $11.4 \%$ \\
\hline & $\begin{array}{l}\text { Quarter } 4 \\
\text { (most } \\
\text { deprived) }\end{array}$ & $2,069,920$ & $5.1 \%$ & $11.7 \%$ \\
\hline
\end{tabular}

LTN = low traffic neighbourhood.

a The total number across London gives the number of people, except for car ownership and employment, where it is number of households. People of Gypsy or Traveller origin are included in the 'other' group in analyses of ethnicity. Deprivation quarters are defined at the area level, relative to London. The percentages presented are row percentages, see Appendix B for the underlying numbers plus column percentages.

However, this does not necessarily mean that LTNs are always implemented equitably across a district.

\subsection{How does the equity of LTN implementation vary by district?}

Of the 33 districts in London, 10 implemented no new LTNs between March and September 2020, while Redbridge and Wandsworth introduced several but shortly after removed them. Among the remaining 21 districts, the proportion of residents covered by new LTNs ranged from $1 \%$ in Greenwich to $17 \%$ in Hackney, plus an outlier value of 55\% in the very small City of London. At the district level, the percentage of residents living in LTNs was highly correlated with lower car ownership (Spearman correlation $=-0.66, \mathrm{p}<0.001$, with the districts' number of cars per capita: See Appendix C). It was also correlated with greater ethnic diversity (Spearman correlation $=0.45, p=0.009$, with the proportion of BAME people in the district) and greater district-level deprivation (Spearman correlation $=0.51, p=0.003$, with districts' mean deprivation rank).

Next, we examined the equity of LTN implementation within districts with regard to ethnicity, disability, and area deprivation. We found that disability showed less spatial variation within districts, and perhaps partly for this reason, there was little difference between the proportion of disabled versus non-disabled people living in LTNs (difference always $<2 \%$ and usually $<0.2 \%$ : see Appendix C).

By contrast, we found larger differences with respect to ethnicity and area deprivation, as tabulated in Appendix $\mathrm{C}$ and shown graphically in Fig. 4. In this Figure, each circle represents a district, with circle size reflecting the proportion of district inhabitants living in an LTN. The
Table 2

Demographic and socio-economic composition of residents living inside an LTN versus those living in nearby areas that touch a boundary road (column percentages).

\begin{tabular}{|c|c|c|c|c|}
\hline & & $\begin{array}{l}\text { Living in } \\
\text { London (all) } \\
(N= \\
8,173,941 \\
\text { individuals) }\end{array}$ & $\begin{array}{l}\text { Living in areas } \\
\text { fully inside } \\
\text { LTN }(N= \\
150,279 \\
\text { individuals) }\end{array}$ & $\begin{array}{l}\text { Living in nearby } \\
\text { non-LTN areas } \\
\text { that touch } \\
\text { boundary roads } \\
\text { ( } N=236,986 \\
\text { individuals) }\end{array}$ \\
\hline All & & $100 \%$ & $100 \%$ & $100 \%$ \\
\hline \multirow[t]{4}{*}{ Age } & 0 to 4 & $7.2 \%$ & $7.0 \%$ & $6.9 \%$ \\
\hline & 5 to 17 & $14.9 \%$ & $14.1 \%$ & $12.7 \%$ \\
\hline & 18 to 64 & $66.8 \%$ & $69.4 \%$ & $71.8 \%$ \\
\hline & $65+$ & $11.1 \%$ & $9.5 \%$ & $8.5 \%$ \\
\hline \multirow[t]{4}{*}{ Ethnicity } & White & $59.7 \%$ & $57.8 \%$ & $56.1 \%$ \\
\hline & Black & $13.3 \%$ & $19.4 \%$ & $17.3 \%$ \\
\hline & Asian & $18.5 \%$ & $13.5 \%$ & $17.0 \%$ \\
\hline & $\begin{array}{l}\text { Mixed or } \\
\text { other }\end{array}$ & $8.5 \%$ & $9.3 \%$ & $9.7 \%$ \\
\hline \multirow[t]{3}{*}{ Disability } & $\begin{array}{l}\text { Not } \\
\text { disabled }\end{array}$ & $85.8 \%$ & $85.6 \%$ & $86.6 \%$ \\
\hline & $\begin{array}{l}\text { Limited a } \\
\text { little }\end{array}$ & $7.4 \%$ & $7.4 \%$ & $7.0 \%$ \\
\hline & $\begin{array}{l}\text { Limited a } \\
\text { lot }\end{array}$ & $6.7 \%$ & $7.0 \%$ & $6.4 \%$ \\
\hline $\begin{array}{l}\text { Household } \\
\text { car }\end{array}$ & None & $41.6 \%$ & $52.7 \%$ & $54.4 \%$ \\
\hline ownership & $\begin{array}{l}1 \text { or more } \\
\text { cars }\end{array}$ & $58.4 \%$ & $47.3 \%$ & $45.6 \%$ \\
\hline Household & $\begin{array}{l}\text { Any } \\
\text { employed } \\
\text { adult }\end{array}$ & $71.8 \%$ & $72.0 \%$ & $73.9 \%$ \\
\hline employment & $\begin{array}{l}\text { No } \\
\text { employed } \\
\text { adult }\end{array}$ & $28.2 \%$ & $28.0 \%$ & $26.1 \%$ \\
\hline Area & $\begin{array}{l}\text { Quarter 1 } \\
\text { (least } \\
\text { deprived) }\end{array}$ & $23.7 \%$ & $13.0 \%$ & $9.6 \%$ \\
\hline \multirow[t]{3}{*}{ deprivation } & Quarter 2 & $25.0 \%$ & $18.4 \%$ & $24.6 \%$ \\
\hline & Quarter 3 & $26.0 \%$ & $32.6 \%$ & $33.4 \%$ \\
\hline & $\begin{array}{l}\text { Quarter } 4 \\
\text { (most } \\
\text { deprived) }\end{array}$ & $25.3 \%$ & $36.0 \%$ & $32.4 \%$ \\
\hline
\end{tabular}

LTN = low traffic neighbourhood. Column percentages calculated with reference to the total number of individuals, except for car ownership and employment where they are calculated with reference to the total number of households.

results present relative differences (percentage ratios): the y-axis shows the percentage of BAME individuals living in LTNs divided by the percentage of White individuals living in LTNs. The x-axis shows the equivalent for area deprivation, $50 \%$ most deprived divided by $50 \%$ least deprived. The top-right quadrant therefore covers districts in which higher proportion of BAME people than White people live in LTNs, and a higher proportion of people from more deprived areas live in LTNs than people from less deprived areas. The black crosses show the median district values. Equivalent comparisons based on absolute differences rather than ratios are provided in Appendix C.

Fig. 3 shows considerable variation between districts in the distribution of LTNs by deprivation and by ethnicity. There are districts where new LTNs have been concentrated in more diverse and deprived neighbourhoods. Others have initially concentrated new LTNs in whiter and more affluent neighbourhoods. This wide variation in implementation practice was not associated with Outer versus Inner London status, the size of the LTN program, the average deprivation rank of the district, nor the proportion of district residents who were BAME (all $p>$ 0.2 in Spearman correlations between these four variables and the percentage ratio for deprivation ( $\mathrm{x}$-axis) or ethnicity (y-axis)).

London's devolved governance system means that a generally equitable distribution at a pan-London and a micro-level can co-exist with a more mixed picture at the district level. For deprivation, the pan-London 


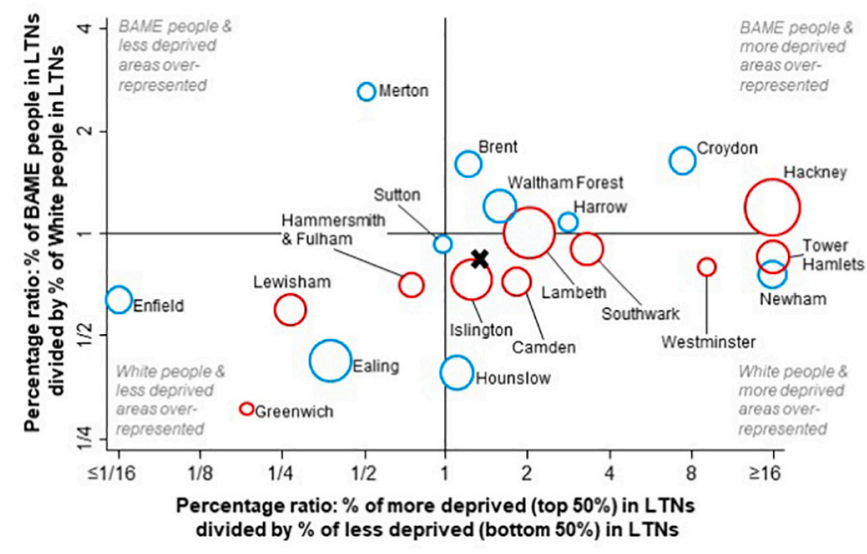

Fig. 4. Relative differences by ethnicity and area deprivation in which residents live inside LTNs, by district.

BAME $=$ Black, Asian and Minority Ethnic. LTN = low traffic neighbourhood. This graph excludes the City of London, which is very small, and excludes 12 districts that did not introduce any LTNs. Each circle represents a district, with circle size proportional to the overall proportion of residents living in new LTNs. Outer London districts are marked in blue, inner London ones in red. The $y$-axis shows the percentage of BAME individuals living in LTNs divided by the percentage of White individuals. The $\mathrm{x}$-axis shows the equivalent for deprivation, defining $50 \%$ most/least deprived relative to London as a whole. The black cross shows the median district value for these two variables. In chi-squared tests for statistical significance, all districts are significantly different from the null for deprivation $(\mathrm{p}<0.001)$ except Sutton $(\mathrm{p}>0.05)$, and all are significantly different from the null for ethnicity $(\mathrm{p} \leq 0.007)$ except Sutton and Lambeth $(p>0.05)$. For a tabulation of these results, see Appendix $C$.

difference between more versus less deprived areas was somewhat larger than that of the typical district: 2.2-fold pan-London versus 1.4fold district median, for the relative difference between the proportion of people from more deprived areas who lived in LTNs divided by the proportion of people from less deprived areas (see Appendix C). This suggests that people from more deprived areas were more likely to live in new LTNs in part because more deprived local authorities created more LTNs and in part because individual local authorities tended to prioritise their more deprived areas. For ethnicity, the pan-London results were slightly positive (percentage ratio 1.08 , i.e. $+8 \%$ relative difference, for the proportion of BAME people living in an LTN divided by the proportion of White people), but the median district-level effect was slightly negative (percentage ratio 0.83 , i.e. $-17 \%$ relative difference). This indicates that individual districts have not systematically been prioritising more ethnically diverse areas. Instead, the higher proportion of BAME people living in new LTNs at the London level was driven by more ethnically diverse districts implementing more LTNs in total.

Both in the pan-London and in our nearby area analysis, we had found different patterns for Black and Asian Londoners. Specifically, Black Londoners are more likely to live in LTNs than White Londoners, but Asian Londoners are less likely. Hence, we also compared at district level what proportion of Asian and White Londoners live in LTNs (Table A8 in Appendix C), to explore to what extent there was consistency across districts. The median across all districts shows a gap of $0.7 \%$ between the proportion of White minus the proportion of Asian residents in LTNs. Among districts that had implemented LTNs, there was substantial variation. In three of the districts, Asian residents were more likely than White residents to live in a LTN (maximum 2.8 times more likely in Merton). The groups were similar in eight, and Asians were less likely to live in LTNs in the remaining nine (maximum 5 times less likely in Hounslow).

Finally, in this sub-section, we present Table 3 showing a different way of calculating equity in relation to area deprivation at the district
Table 3

Alternative comparison of deprivation metrics by district: mean deprivation percentile inside versus outside LTNs.

\begin{tabular}{|c|c|c|c|}
\hline & $\begin{array}{l}\text { A: mean deprivation } \\
\text { percentile inside } \\
\text { LTN }\end{array}$ & $\begin{array}{l}\text { B: Mean deprivation } \\
\text { percentile outside } \\
\text { LTN }\end{array}$ & $\begin{array}{l}\text { Difference A } \\
\text { minus B }\end{array}$ \\
\hline Enfield & $24 \%$ & $62 \%$ & $-37 \%$ \\
\hline Greenwich & $32 \%$ & $60 \%$ & $-27 \%$ \\
\hline Lewisham & $49 \%$ & $66 \%$ & $-17 \%$ \\
\hline Ealing & $41 \%$ & $55 \%$ & $-14 \%$ \\
\hline Wandsworth & $28 \%$ & $37 \%$ & $-9 \%$ \\
\hline \multicolumn{4}{|l|}{ Hammersmith \& } \\
\hline Fulham & $47 \%$ & $53 \%$ & $-6 \%$ \\
\hline Sutton & $24 \%$ & $29 \%$ & $-5 \%$ \\
\hline Newham & $70 \%$ & $74 \%$ & $-4 \%$ \\
\hline Waltham Forest & $59 \%$ & $61 \%$ & $-2 \%$ \\
\hline Islington & $66 \%$ & $67 \%$ & $-1 \%$ \\
\hline Hounslow & $52 \%$ & $51 \%$ & $0 \%$ \\
\hline Hackney & $80 \%$ & $79 \%$ & $2 \%$ \\
\hline Lambeth & $65 \%$ & $62 \%$ & $3 \%$ \\
\hline Merton & $34 \%$ & $31 \%$ & $3 \%$ \\
\hline Camden & $52 \%$ & $47 \%$ & $6 \%$ \\
\hline Brent & $68 \%$ & $61 \%$ & $7 \%$ \\
\hline Southwark & $72 \%$ & $63 \%$ & $10 \%$ \\
\hline Harrow & $43 \%$ & $32 \%$ & $10 \%$ \\
\hline Tower Hamlets & $82 \%$ & $68 \%$ & $14 \%$ \\
\hline Croydon & $70 \%$ & $51 \%$ & $19 \%$ \\
\hline Westminster & $66 \%$ & $46 \%$ & $20 \%$ \\
\hline
\end{tabular}

Deprivation percentiles are calculated by ranking each LSOA from 0 to 100 across London as a whole, with 100 corresponding to the highest level of deprivation.

level. This compares the average area deprivation percentile for those living inside versus outside LTNs, with the percentiles calculated relative to London as a whole and ranging from 0 (most affluent) to 1 (most deprived). While most district results are similar to that generated by the earlier metrics, for Hackney and Newham (which have relatively few affluent areas, none of which saw LTNs implemented) a highly positive picture in Fig. 3 becomes neutral in Table 3. Of the 20 large London districts that implemented LTNs, Hackney and Newham are the two most homogenous with regard to area deprivation (as judged by the standard deviation of deprivation percentiles), making it somewhat harder for them to score highly on the Table 3 metric. By contrast, districts with more variable levels of deprivation have greater scope to score high or low: as exemplified by Enfield and Westminster, the two districts in Table 3 with the greatest internal variation in area deprivation levels.

\subsection{Discussion of findings}

Across London as a whole, new 2020 LTNs tend to have been implemented in more deprived neighbourhoods, and are slightly more likely to have been implemented in areas with higher proportions of Black, Asian, and Minority Ethnic residents. Transport for London used equity criteria related to deprivation in its planning processes, unlike many authorities (Lee et al., 2017), and this may have affected those outcomes. Micro-level equity is reasonably good, in that there do not seem to be large systemic differences between the demographic profile of those living in output areas entirely within LTNs and those living in nearby areas that touch boundary roads.

Having said this, within this broadly equitable picture there were some disparities. While overall BAME Londoners were slightly more likely than White Londoners to live in a new LTN (3.9\% versus $3.6 \%$ ), this varied by ethnic group. Among Black Londoners, 5.0\% lived in a new LTN compared to $3.6 \%$ of White Londoners. However, Asian Londoners were slightly less likely than White Londoners to live in a new LTN $(2.9 \%$ did, meaning they were $-0.7 \%$ less likely than White Londoners to live in an LTN). Asian Londoners were also somewhat less likely to live inside an LTN than in a nearby boundary area. These 
differences may reflect various factors, including the slightly higher proportion of Asians who live on a high street or main road compared to White or Black Londoners (10\% versus 8-9\%, see Aldred and Verlinghieri, 2020). The proportion of Asian Londoners living in LTNs would also have been higher if LTNs had remained in place in Tooting within Wandsworth and/or in South Ilford within Redbridge, both neighbourhoods with large Asian populations. However, these two districts implemented but then removed their LTNs within the study period.

Some of the relatively positive picture regarding deprivation is due to a failure: the failure of several more affluent and more car-dependent districts to implement anything. Less affluent districts with lower car ownership were likely both more committed to the concept of LTNs and found them politically easier to implement. Twelve districts did not introduce any LTNs between March and September 2020 (or in two cases, introduced them but removed them soon after), so no resident in any group benefited there. As such, although we have focused in this paper on demographic and socioeconomic differences, arguably the largest inequality in London at the city level is the postcode lottery between districts. Among those districts that did introduce measures, we found that the 'typical' district was more likely to introduce LTNs in its more deprived areas but was also slightly more likely to favour its White residents. The latter effect is relatively small, however, and both effects mask very considerable variation between districts.

Reasons for this variation are not clear but may reflect variation across the capital in the political and policy processes that designed and implemented this first wave of LTNs. For example, Enfield initially introduced LTNs in areas that fitted a 'White, middle-class' profile, where local people had been strongly campaigning for LTNs. A key rationale for starting with these areas was that the surrounding main roads had previously received interventions such as new cycle tracks to which the LTNs could connect. Enfield is therefore an interesting example in highlighting the potential for competing legitimate considerations, including competing 'equity' considerations, in prioritising LTN locations. Advantages of the selected areas in Enfield included extensive public engagement; creating a more coherent cycling network; and 'equity by road type' in the sense that that some of the boundary roads surrounding LTNs had themselves also benefited from active travel interventions. The selection did, however, mean that the initial distribution of LTNs across the district was not equitable with respect to demographic and socioeconomic equity - although proposals for further LTNs in the east of Enfield would redress this by focusing on poorer parts of the district.

We are also aware that some districts initially implemented emergency measures based on schemes already under consultation before the Covid-19 pandemic. This is unsurprising given the very short timeframe (around 4 months) within which districts were expected to submit and then execute their plans, but may have meant that equity was less a consideration than expediency for the very first schemes. For example, Southwark implemented one of its first measures in the most affluent part of the district, based on schemes already under way in that area. By contrast, several of Southwark's most recent LTNs are being implemented in areas specifically chosen on grounds of equity, including the presence of poor health indicators such as childhood obesity rates, with funding from the charitable arm of the local hospital trust.

The LTNs implemented first may therefore often have been ones that happened to be easiest for districts to do quickly, rather than reflecting the nature of their fuller plans for further measures. It will be interesting to examine whether, as this implies, districts converge somewhat over time as funding to implement further LTNs is made available. We recommend that as the LTN programme develops, the equity of the distribution of LTNs is monitored at both a city and district level, so that adjustments can be made as necessary. This is particularly important for those districts that our research identifies as having initially installed LTNs in less diverse and/or less deprived neighbourhoods; we would advise these districts to roll our further LTNs that place priority on rectifying this. The reasons for variations between districts would be a useful focus for future qualitative and quantitative research. Further research could also examine the extent to which LTNs improve active travel connectivity, by joining up what have been called 'low-stress' routes to destinations, as well as developing a motor traffic connectivity metric which might start to 'objectively' identify areas with low traffic neighbourhood characteristics (i.e. a contiguous area with low local motor traffic connectivity).

One of the limitations of this research is that it is only a snapshot of the first phase of LTN implementation in London. Another important limitation is our use of 2011 UK Census data; unfortunately, England only conducts a Census once every ten years. It is, however, reassuring that when we made comparisons between 2011 and more recent data for car ownership and deprivation, we found a high correlation over time and no differential change between LTN and non-LTN areas. A further limitation is our use of area-based metrics to compare individuals living fully inside an LTN with individuals living in nearby areas. This prevented us from making a direct comparison between individuals actually living on boundary roads versus those on internal residential streets. We note, however, that our finding of relatively little difference between these two types of areas accords with previous evidence that there is generally little demographic or socio-economic difference between London residents living on main roads or high streets (which are more likely to be boundary roads) versus residential streets (more likely to be inside an LTN) (Aldred and Verlinghieri, 2020).

\section{Conclusions}

This study used a spatial equity approach to examine the equity distribution of new LTNs implemented in London between March 2020 to September 2020. Specifically, we analysed the LTNs coverage across London and within individual districts in relation to key dimensions of equity (e.g. disability, ethnicity, deprivation). We also examined potential socio-demographic differences between LTNs and nearby boundary areas.

We found that the first wave of LTNs in London has been broadly equitable across London as a whole, and also at the micro-level comparing residents within LTNs to their immediate neighbours. There is, however, considerable variation between districts in the extent to which they have introduced LTNs in a way that is equitable with regard to ethnicity and deprivation. In particular, the district-led approach has left a third of London districts without any LTNs implemented during this period at all, these disproportionately being the most car-dependent and car-dominated districts, with lower public transport accessibility. This has particularly problematic implications for residents living on low incomes and without private vehicle access within these districts. Thus, while LTNs may have strong potential to improve equity of access to high-quality active travel infrastructure, our results suggest that this will not automatically happen everywhere. The same may be true for other contexts with devolved governance and is a reason to monitor district-level as well as overall equity when similar initiatives are to be adopted. 
Appendix A. Additional methodological information

\section{A.1. Implementation of LTNs, and details of LTNs by district}

The introduction of emergency LTNs has involved Transport for London (TfL) decision-making as well as the 33 districts that manage the roads involved. TfL had already been working on guidance for 'Liveable Neighbourhoods', in which LTN and similar small area interventions were prominent (TfL, 2019). These interventions were justified in relation to the 'Healthy Streets' approach, which foregrounds not just harm reduction but the potential for streets to promote well-being (for instance, through physical activity). In May 2020, TfL developed its Strategic Neighbourhood Analysis Guidance, which identified potential LTN areas based on a mix of criteria: modelled through motor traffic, walking and cycling injuries, cycling connectivity, pavement widths, population density, number of schools, deprivation levels, total population, child population, and car ownership (TfL, 2020: 6). This was described as a guide rather than a rule, although districts were expected to refer to it when proposing schemes to TfL.

TfL submitted on behalf of districts an application to the Department for Transport's Tranche 1 Emergency Active Travel Fund (which funded many of the schemes discussed here), although not all districts bid or were successful in bidding. In other cases, funding was provided by TfL through other mechanisms, such as Local Implementation Plans. Hence, not only districts but also TfL and in some cases DfT had a say in which schemes were brought forward and implemented. Moreover, even where funding was agreed, this did not always translate into successful scheme implementation, with schemes being removed quickly in two districts following protests and other schemes being delayed. Thus, while deprivation was included by TfL (2020) as one criterion to consider, it is important to examine to what extent this is apparent in the schemes that were actually implemented.

Note that the analysis here represents a snapshot of LTNs that had been introduced by the end of September and were still in place in October. Individual district results should be seen in this context: early high levels of (in)equity in implementation may have changed. For instance, Lewisham decided to substantially reduce its LTN in November 2021, but it was still in place by the end of October, so it is included in this analysis. Conversely, districts such as Hackney introduced many more measures during October, but these are not included.

Table A1: Summary of LTN development by district.

\begin{tabular}{|c|c|}
\hline District & New LTNs (measures introduced between March-September 2020, and in place by the end of October 2020). \\
\hline City of London & $\begin{array}{l}\text { While not referring to LTNs, City of London has been implementing an ambitious programme of motor traffic reduction, including bus-bike corridors on } \\
\text { major arteries and modal filtering in smaller streets. }\end{array}$ \\
\hline Barking and Dagenham & No new LTNs as of September 2020. \\
\hline Barnet & No new LTNs as of September 2020. \\
\hline Bexley & No new LTNs as of September 2020. \\
\hline Brent & In Summer 2020, Brent began implementing LTNs, initially in Stonebridge and Harlesden, and Wembley Central. More are planned. \\
\hline Bromley & No new LTNs as of September 2020. \\
\hline Camden & Camden implemented LTN schemes around Camden Town, Gospel Oak, and Gray's Inn, and modal filtering around Covent Garden. \\
\hline Croydon & Croydon implemented LTN schemes in Norwood and Broad Green. \\
\hline Ealing & A series of LTNs implemented mostly to the South of the district, around the border with Hounslow (one is a combined scheme). \\
\hline Enfield & Two LTNs in the South-West of the district. \\
\hline Greenwich & A small amount of modal filtering in the North-West of the district. \\
\hline Hackney & $\begin{array}{l}\text { Hackney has a long-standing programme of modal filtering to reduce through traffic from neighbourhoods and continued this across the district. Since } \\
\text { September 2020, more have been introduced, and the district plans to introduce them across the rest of the district in the longer-term. }\end{array}$ \\
\hline $\begin{array}{l}\text { Hammersmith and } \\
\text { Fulham }\end{array}$ & $\begin{array}{l}\text { Hammersmith and Fulham introduced one 'traffic scheme' in SW6. This differs from other LTNs in allowing through all district residents and taxis. It is } \\
\text { likely to have less of an impact in reducing through traffic than other LTNs. }\end{array}$ \\
\hline Haringey & No new LTNs as of September 2020. \\
\hline Harrow & Harrow introduced several small LTNs in the centre of the district. \\
\hline Havering & No new LTNs as of September 2020. \\
\hline Hillingdon & No new LTNs as of September 2020. \\
\hline Hounslow & Hounslow has introduced LTNs around the areas of Chiswick and Isleworth, as well as at the district boundary with Ealing. \\
\hline Islington & Islington has rolled out a number of LTNs, so far, most around the South of the district, and plans more. \\
\hline Kensington and Chelsea & No new LTNs as of September 2020. \\
\hline Kingston upon Thames & $\begin{array}{l}\text { Kingston has introduced several modal filters at various points in the district to reduce through motor traffic; however, we have not drawn them as 'LTNs' } \\
\text { as they are separate filters in different neighbourhoods. }\end{array}$ \\
\hline Lambeth & Lambeth has introduced LTNs across the centre of the district, as well as one in the North near Oval. \\
\hline Lewisham & $\begin{array}{l}\text { Lewisham introduced one LTN in Lee Green; they then announced plans to roll this back, but as of the time of writing it remained in place and so is included } \\
\text { on the map. }\end{array}$ \\
\hline Merton & In September, Merton introduced three small LTNs in the East of the district, with more introduced since. \\
\hline Newham & Newham has implemented one larger LTN around the Wanstead/Stratford area, in partnership with Waltham Forest (the LTN straddles the border). \\
\hline Redbridge & Redbridge introduced two LTNs towards the West of the district, but removed them after just over a month after vocal opposition from a group of residents. \\
\hline Richmond upon Thames & Richmond introduced one modal filter towards the West of the district. \\
\hline Southwark & Southwark constructed one larger LTN in Walworth in the north of the district, and have implemented several smaller schemes in Dulwich. \\
\hline Sutton & Sutton have created two LTN areas in Central Sutton and implemented a number of modal filters separately elsewhere in the district. \\
\hline Tower Hamlets & $\begin{array}{l}\text { A larger LTN was implemented to the North-West of the district, by the Hackney border. This formed part of a Liveable Neighbourhood scheme and } \\
\text { includes the modal filtering of a B road, with the creation of new pocket parks. }\end{array}$ \\
\hline Waltham Forest & $\begin{array}{l}\text { Waltham Forest has, like Hackney, a number of longer-standing schemes, in this case more recent via the Mini-Holland programme. Between March and } \\
\text { September, it implemented additional schemes in several areas that had not yet been treated in this way. }\end{array}$ \\
\hline Wandsworth & $\begin{array}{l}\text { Wandsworth introduced LTNs around the Tooting area. Despite initial evidence of the LTNs reducing local traffic and boosting numbers of cyclists, they } \\
\text { were removed after only a few weeks following complaints7. }\end{array}$ \\
\hline Westminster & $\begin{array}{l}\text { Westminster did not build anything specifically called an 'LTN'; however, restrictions on motor traffic entry in some parts of Soho and Covent Garden } \\
\text { (often with the aim of supporting businesses such as restaurants in those areas) have here been included as LTNs, as in Camden. }\end{array}$ \\
\hline
\end{tabular}

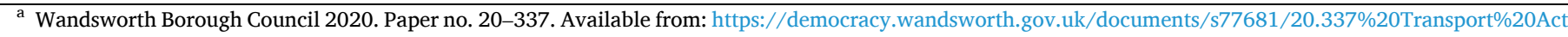
ion\%20Plan.pdf. 
Appendix B. Who lives in new LTNs? Sensitivity analysis for pan-London results, plus results stratified by Inner/Outer London and district

Note: We do not present district level tables for City of London, which is very small, or for 11 districts where $<1 \%$ of the population was covered by new measures. These districts are nonetheless included in our analyses of Inner and Outer London as a whole.

Table A2: Proportion of Londoners living near different types of modal filter interventions, by demographic and socioeconomic characteristics: underlying numbers and column percentages.

\begin{tabular}{|c|c|c|c|c|c|c|c|}
\hline & & \multicolumn{2}{|l|}{ All London } & \multicolumn{2}{|c|}{ Inside LTN } & \multicolumn{2}{|c|}{ Within $500 \mathrm{~m}$ of a modal filter } \\
\hline & & Number $^{\mathrm{a}}$ & Column \% & Number $^{\mathrm{a}}$ & Column \% & Number $^{\mathrm{a}}$ & Column \% \\
\hline All & & $8,173,941$ & $100 \%$ & 302,804 & $100 \%$ & 728,537 & $100 \%$ \\
\hline \multirow{4}{*}{ Age } & 0 to 4 & 591,495 & $7 \%$ & 20,686 & $7 \%$ & 50,101 & $7 \%$ \\
\hline & 5 to 17 & $1,219,899$ & $15 \%$ & 41,005 & $14 \%$ & 94,926 & $13 \%$ \\
\hline & 18 to 64 & $5,457,798$ & $67 \%$ & 212,551 & $70 \%$ & 518,540 & $71 \%$ \\
\hline & $65+$ & 904,749 & $11 \%$ & 28,562 & $9 \%$ & 64,970 & $9 \%$ \\
\hline \multirow[t]{4}{*}{ Ethnicity } & White & $4,879,239$ & $60 \%$ & 175,055 & $58 \%$ & 425,095 & $58 \%$ \\
\hline & Black & $1,088,640$ & $13 \%$ & 54,935 & $18 \%$ & 127,985 & $18 \%$ \\
\hline & Asian & $1,511,546$ & $18 \%$ & 44,197 & $15 \%$ & 103,937 & $14 \%$ \\
\hline & Mixed or other & 694,516 & $8 \%$ & 28,617 & $9 \%$ & 71,520 & $10 \%$ \\
\hline \multirow[t]{3}{*}{ Disability } & Not disabled & $7,016,776$ & $86 \%$ & 259,709 & $86 \%$ & 628,533 & $86 \%$ \\
\hline & Limited a little & 605,501 & $7 \%$ & 22,121 & $7 \%$ & 51,672 & $7 \%$ \\
\hline & Limited a lot & 551,664 & $7 \%$ & 20,974 & $7 \%$ & 48,332 & $7 \%$ \\
\hline \multirow{2}{*}{$\begin{array}{l}\text { Household car } \\
\text { ownership }\end{array}$} & None & $1,357,251$ & $42 \%$ & 67,323 & $53 \%$ & 170,354 & $55 \%$ \\
\hline & 1 or more cars & $1,908,922$ & $58 \%$ & 59,857 & $47 \%$ & 140,513 & $45 \%$ \\
\hline \multirow{6}{*}{$\begin{array}{l}\text { Household } \\
\text { employment } \\
\text { Area } \\
\text { deprivation }\end{array}$} & Any employed adult & $2,345,738$ & $72 \%$ & 92,357 & $73 \%$ & 226,641 & $73 \%$ \\
\hline & No employed adult & 920,435 & $28 \%$ & 34,822 & $27 \%$ & 84,226 & $27 \%$ \\
\hline & Quarter 1 (least deprived) & $1,941,076$ & $24 \%$ & 38,887 & $13 \%$ & 95,088 & $13 \%$ \\
\hline & Quarter 2 & $2,040,925$ & $25 \%$ & 52,928 & $17 \%$ & 149,299 & $20 \%$ \\
\hline & Quarter 3 & $2,122,020$ & $26 \%$ & 105,675 & $35 \%$ & 241,089 & $33 \%$ \\
\hline & Quarter 4 (most deprived) & $2,069,920$ & $25 \%$ & 105,314 & $35 \%$ & 243,061 & $33 \%$ \\
\hline
\end{tabular}

LTN = low traffic neighbourhood.

a Number of people, except for car ownership and employment, where it is number of households. People of Gypsy or Traveller origin are included in the 'other' group in analyses of ethnicity. Deprivation quarters defined relative to London.

Table A3: Proportion of Londoners living near different types of modal filter interventions, by demographic and socioeconomic characteristics: SENSITIVITY ANALYSIS, WHOLE OF LONDON.

\begin{tabular}{|c|c|c|c|c|c|}
\hline & & Number $^{\mathrm{a}}$ & Inside LTN & Inside LTN, in output areas $100 \%$ inside LTNs & Within $500 \mathrm{~m}$ of a modal filter \\
\hline All & & $8,173,941$ & $3.7 \%$ & $1.8 \%$ & $8.9 \%$ \\
\hline \multirow[t]{4}{*}{ Age } & 0 to 4 & 591,495 & $3.5 \%$ & $1.8 \%$ & $8.5 \%$ \\
\hline & 5 to 17 & $1,219,899$ & $3.4 \%$ & $1.7 \%$ & $7.8 \%$ \\
\hline & 18 to 64 & $5,457,798$ & $3.9 \%$ & $1.9 \%$ & $9.5 \%$ \\
\hline & $65+$ & 904,749 & $3.2 \%$ & $1.6 \%$ & $7.2 \%$ \\
\hline \multirow[t]{4}{*}{ Ethnicity } & White & $4,879,239$ & $3.6 \%$ & $1.8 \%$ & $8.7 \%$ \\
\hline & Black & $1,088,640$ & $5.0 \%$ & $2.7 \%$ & $11.8 \%$ \\
\hline & Asian & $1,511,546$ & $2.9 \%$ & $1.3 \%$ & $6.9 \%$ \\
\hline & Mixed or other & 694,516 & $4.1 \%$ & $2.0 \%$ & $10.3 \%$ \\
\hline \multirow[t]{3}{*}{ Disability } & Not disabled & $7,016,776$ & $3.7 \%$ & $1.8 \%$ & $9.0 \%$ \\
\hline & Limited a little & 605,501 & $3.7 \%$ & $1.8 \%$ & $8.5 \%$ \\
\hline & Limited a lot & 551,664 & $3.8 \%$ & $1.9 \%$ & $8.8 \%$ \\
\hline \multirow{4}{*}{$\begin{array}{l}\text { Household car } \\
\text { ownership } \\
\text { Household } \\
\text { employment }\end{array}$} & None & $1,357,251$ & $5.0 \%$ & $2.4 \%$ & $12.6 \%$ \\
\hline & 1 or more cars & $1,908,922$ & $3.1 \%$ & $1.6 \%$ & $7.4 \%$ \\
\hline & Any employed adult & $2,345,738$ & $3.9 \%$ & $1.9 \%$ & $9.7 \%$ \\
\hline & No employed adult & 920,435 & $3.8 \%$ & $1.9 \%$ & $9.2 \%$ \\
\hline Area & Quarter 1 (least deprived) & $1,941,076$ & $2.0 \%$ & $1.0 \%$ & $4.9 \%$ \\
\hline \multirow[t]{3}{*}{ deprivation } & Quarter 2 & $2,040,925$ & $2.6 \%$ & $1.4 \%$ & $7.3 \%$ \\
\hline & Quarter 3 & $2,122,020$ & $5.0 \%$ & $2.3 \%$ & $11.4 \%$ \\
\hline & Quarter 4 (most deprived) & $2,069,920$ & $5.1 \%$ & $2.6 \%$ & $11.7 \%$ \\
\hline
\end{tabular}

LTN $=$ low traffic neighbourhood.

a Number of people, except for car ownership and employment, where it is number of households. People of Gypsy or Traveller origin are included in the 'other' group in analyses of ethnicity. Deprivation quarters defined relative to London.

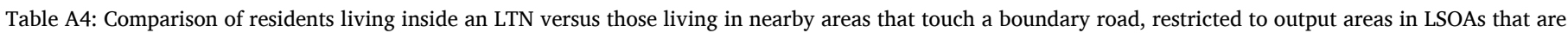
either fully inside or fully outside.

\begin{tabular}{|c|c|c|c|}
\hline & & $\begin{array}{l}\% \text { living in areas fully inside LTN }(N=128,472 \\
\text { individuals) }\end{array}$ & $\begin{array}{l}\text { \% living in nearby non-LTN areas that touch boundary roads }(N=216,056 \\
\text { individuals) }\end{array}$ \\
\hline All & & $100 \%$ & $100 \%$ \\
\hline \multirow[t]{3}{*}{ Age } & 0 to 4 & $7.1 \%$ & $6.9 \%$ \\
\hline & 5 to 17 & $13.9 \%$ & $12.8 \%$ \\
\hline & 18 to 64 & $69.7 \%$ & $71.8 \%$ \\
\hline
\end{tabular}


(continued)

\begin{tabular}{|c|c|c|c|}
\hline & & $\begin{array}{l}\text { \% living in areas fully inside LTN }(N=128,472 \\
\text { individuals) }\end{array}$ & $\begin{array}{l}\text { \% living in nearby non-LTN areas that touch boundary roads }(N=216,056 \\
\text { individuals) }\end{array}$ \\
\hline & $65+$ & $9.2 \%$ & $8.5 \%$ \\
\hline \multirow[t]{4}{*}{ Ethnicity } & White & $58.4 \%$ & $56.4 \%$ \\
\hline & Black & $18.9 \%$ & $17.0 \%$ \\
\hline & Asian & $13.5 \%$ & $16.9 \%$ \\
\hline & Mixed or other & $9.2 \%$ & $9.7 \%$ \\
\hline \multirow[t]{3}{*}{ Disability } & Not disabled & $85.8 \%$ & $86.6 \%$ \\
\hline & Limited a little & $7.3 \%$ & $7.0 \%$ \\
\hline & Limited a lot & $6.9 \%$ & $6.4 \%$ \\
\hline $\begin{array}{l}\text { Household } \\
\text { car }\end{array}$ & None & $51.9 \%$ & $54.0 \%$ \\
\hline ownership & 1 or more cars & $48.1 \%$ & $46.0 \%$ \\
\hline Household & Any employed adult & $72.5 \%$ & $74.1 \%$ \\
\hline employment & No employed adult & $27.5 \%$ & $25.9 \%$ \\
\hline Area & $\begin{array}{l}\text { Quarter } 1 \text { (least } \\
\text { deprived) }\end{array}$ & $14.0 \%$ & $9.7 \%$ \\
\hline \multirow[t]{3}{*}{ deprivation } & Quarter 2 & $19.4 \%$ & $26.3 \%$ \\
\hline & Quarter 3 & $32.4 \%$ & $32.9 \%$ \\
\hline & $\begin{array}{l}\text { Quarter } 4 \text { (most } \\
\text { deprived) }\end{array}$ & $34.2 \%$ & $31.1 \%$ \\
\hline
\end{tabular}

LTN = low traffic neighbourhood.

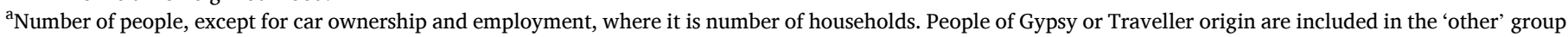
in analyses of ethnicity. Deprivation quarters defined relative to London.

Table A5.1: Proportion of Londoners living near different types of modal filter interventions, by demographic and socioeconomic characteristics: INNER LONDON.

\begin{tabular}{|c|c|c|c|c|}
\hline & & Number & Inside LTN & Within $500 \mathrm{~m}$ of a modal filter \\
\hline All & & $2,923,548$ & $6.1 \%$ & $15.6 \%$ \\
\hline \multirow[t]{4}{*}{ Age } & 0 to 4 & 203,357 & $5.5 \%$ & $14.2 \%$ \\
\hline & 5 to 17 & 379,283 & $5.9 \%$ & $14.5 \%$ \\
\hline & 18 to 64 & $2,080,175$ & $6.2 \%$ & $16.1 \%$ \\
\hline & $65+$ & 260,733 & $5.9 \%$ & $14.6 \%$ \\
\hline \multirow[t]{4}{*}{ Ethnicity } & White & $1,765,999$ & $6.0 \%$ & $15.5 \%$ \\
\hline & Black & 480,750 & $7.3 \%$ & $17.7 \%$ \\
\hline & Asian & 387,042 & $5.0 \%$ & $13.3 \%$ \\
\hline & Mixed or other & 289,757 & $5.9 \%$ & $16.0 \%$ \\
\hline \multirow[t]{3}{*}{ Disability } & Not disabled & $2,524,999$ & $6.0 \%$ & $15.6 \%$ \\
\hline & Limited a little & 202,445 & $6.4 \%$ & $15.9 \%$ \\
\hline & Limited a lot & 196,104 & $6.4 \%$ & $15.9 \%$ \\
\hline Household car & None & 710,695 & $6.7 \%$ & $17.8 \%$ \\
\hline ownership & 1 or more cars & 550,693 & $5.5 \%$ & $13.7 \%$ \\
\hline Household & Any employed adult & 914,588 & $6.1 \%$ & $16.0 \%$ \\
\hline employment & No employed adult & 346,800 & $6.3 \%$ & $16.2 \%$ \\
\hline Area & Quarter 1 (least deprived) & 417,872 & $1.8 \%$ & $7.0 \%$ \\
\hline \multirow[t]{3}{*}{ deprivation } & Quarter 2 & 684,321 & $3.9 \%$ & $13.0 \%$ \\
\hline & Quarter 3 & 839,443 & $7.8 \%$ & $18.9 \%$ \\
\hline & Quarter 4 (most deprived) & 981,912 & $7.9 \%$ & $18.3 \%$ \\
\hline
\end{tabular}

See notes to Table A4.

Table A5.2: Proportion of Londoners living near different types of modal filter interventions, by demographic and socioeconomic characteristics: OUTER LONDON.

\begin{tabular}{|c|c|c|c|c|}
\hline & & Number & Inside LTN & Within $500 \mathrm{~m}$ of a modal filter \\
\hline All & & $5,250,393$ & $2.4 \%$ & $5.2 \%$ \\
\hline \multirow[t]{4}{*}{ Age } & 0 to 4 & 388,138 & $2.5 \%$ & $5.5 \%$ \\
\hline & 5 to 17 & 840,616 & $2.2 \%$ & $4.7 \%$ \\
\hline & 18 to 64 & $3,377,623$ & $2.5 \%$ & $5.5 \%$ \\
\hline & $65+$ & 644,016 & $2.0 \%$ & $4.2 \%$ \\
\hline \multirow[t]{4}{*}{ Ethnicity } & White & $3,113,240$ & $2.2 \%$ & $4.9 \%$ \\
\hline & Black & 607,890 & $3.3 \%$ & $7.1 \%$ \\
\hline & Asian & $1,124,504$ & $2.2 \%$ & $4.7 \%$ \\
\hline & Mixed or other & 404,759 & $2.8 \%$ & $6.2 \%$ \\
\hline \multirow[t]{3}{*}{ Disability } & Not disabled & $4,491,777$ & $2.4 \%$ & $5.2 \%$ \\
\hline & Limited a little & 403,056 & $2.3 \%$ & $4.8 \%$ \\
\hline & Limited a lot & 355,560 & $2.3 \%$ & $4.8 \%$ \\
\hline Household car & None & 646,556 & $3.0 \%$ & $6.8 \%$ \\
\hline ownership & 1 or more cars & $1,358,229$ & $2.2 \%$ & $4.8 \%$ \\
\hline Household & Any employed adult & $1,431,150$ & $2.5 \%$ & $5.6 \%$ \\
\hline employment & No employed adult & 573,635 & $2.3 \%$ & $4.9 \%$ \\
\hline Area & Quarter 1 (least deprived) & $1,523,204$ & $2.1 \%$ & $4.3 \%$ \\
\hline \multirow[t]{3}{*}{ deprivation } & Quarter 2 & $1,356,604$ & $1.9 \%$ & $4.4 \%$ \\
\hline & Quarter 3 & $1,282,577$ & $3.1 \%$ & $6.4 \%$ \\
\hline & Quarter 4 (most deprived) & $1,088,008$ & $2.5 \%$ & $5.8 \%$ \\
\hline
\end{tabular}


See notes to Table A4.

Table A5.3: Proportion of Londoners living near different types of modal filter interventions, by demographic and socioeconomic characteristics: BRENT.

\begin{tabular}{|c|c|c|c|c|}
\hline & & Number & Inside LTN & Within $500 \mathrm{~m}$ of a modal filter \\
\hline All & & 311,215 & $3.6 \%$ & $6.5 \%$ \\
\hline \multirow[t]{4}{*}{ Age } & 0 to 4 & 22,446 & $3.8 \%$ & $7.3 \%$ \\
\hline & 5 to 17 & 47,918 & $3.9 \%$ & $7.1 \%$ \\
\hline & 18 to 64 & 208,175 & $3.5 \%$ & $6.4 \%$ \\
\hline & $65+$ & 32,676 & $3.7 \%$ & $6.1 \%$ \\
\hline \multirow[t]{4}{*}{ Ethnicity } & White & 112,560 & $2.6 \%$ & $5.1 \%$ \\
\hline & Black & 58,632 & $5.6 \%$ & $9.8 \%$ \\
\hline & Asian & 105,986 & $3.7 \%$ & $6.3 \%$ \\
\hline & Mixed or other & 34,037 & $3.4 \%$ & $6.5 \%$ \\
\hline \multirow[t]{3}{*}{ Disability } & Not disabled & 266,333 & $3.6 \%$ & $6.4 \%$ \\
\hline & Limited a little & 23,213 & $3.8 \%$ & $6.8 \%$ \\
\hline & Limited a lot & 21,669 & $4.0 \%$ & $7.2 \%$ \\
\hline Household car & None & 47,419 & $3.8 \%$ & $7.7 \%$ \\
\hline ownership & 1 or more cars & 62,867 & $3.3 \%$ & $5.7 \%$ \\
\hline Household & Any employed adult & 80,437 & $3.4 \%$ & $6.2 \%$ \\
\hline employment & No employed adult & 29,849 & $4.0 \%$ & $7.5 \%$ \\
\hline Area & Quarter 1 (least deprived) & 17,007 & $8.1 \%$ & $12.6 \%$ \\
\hline \multirow[t]{3}{*}{ deprivation } & Quarter 2 & 84,743 & $2.2 \%$ & $3.6 \%$ \\
\hline & Quarter 3 & 114,721 & $2.3 \%$ & $2.9 \%$ \\
\hline & Quarter 4 (most deprived) & 94,744 & $5.7 \%$ & $12.5 \%$ \\
\hline
\end{tabular}

See notes to Table A4.

Table A5.4: Proportion of Londoners living near different types of modal filter interventions, by demographic and socioeconomic characteristics: CAMDEN.

\begin{tabular}{|c|c|c|c|c|}
\hline & & Number & Inside LTN & Within $500 \mathrm{~m}$ of a modal filter \\
\hline All & & 220,338 & $4.3 \%$ & $19.6 \%$ \\
\hline \multirow[t]{4}{*}{ Age } & 0 to 4 & 13,168 & $3.6 \%$ & $16.7 \%$ \\
\hline & 5 to 17 & 25,837 & $4.3 \%$ & $18.5 \%$ \\
\hline & 18 to 64 & 157,356 & $4.3 \%$ & $20.3 \%$ \\
\hline & $65+$ & 23,977 & $4.0 \%$ & $17.5 \%$ \\
\hline \multirow[t]{4}{*}{ Ethnicity } & White & 145,888 & $4.7 \%$ & $19.7 \%$ \\
\hline & Black & 18,060 & $3.5 \%$ & $19.9 \%$ \\
\hline & Asian & 35,446 & $2.9 \%$ & $19.4 \%$ \\
\hline & Mixed or other & 20,944 & $4.1 \%$ & $18.6 \%$ \\
\hline \multirow[t]{3}{*}{ Disability } & Not disabled & 188,507 & $4.2 \%$ & $19.3 \%$ \\
\hline & Limited a little & 16,300 & $4.3 \%$ & $21.2 \%$ \\
\hline & Limited a lot & 15,531 & $4.3 \%$ & $21.6 \%$ \\
\hline Household car & None & 59,595 & $4.3 \%$ & $21.5 \%$ \\
\hline ownership & 1 or more cars & 37,939 & $4.2 \%$ & $16.5 \%$ \\
\hline Household & Any employed adult & 68,880 & $4.5 \%$ & $19.5 \%$ \\
\hline employment & No employed adult & 28,654 & $3.9 \%$ & $19.8 \%$ \\
\hline Area & Quarter 1 (least deprived) & 56,816 & $2.6 \%$ & $5.1 \%$ \\
\hline \multirow[t]{3}{*}{ deprivation } & Quarter 2 & 62,502 & $3.6 \%$ & $17.6 \%$ \\
\hline & Quarter 3 & 52,110 & $8.1 \%$ & $36.5 \%$ \\
\hline & Quarter 4 (most deprived) & 48,910 & $3.0 \%$ & $20.9 \%$ \\
\hline
\end{tabular}

See notes to Table A4.

Table A5.5: Proportion of Londoners living near different types of modal filter interventions, by demographic and socioeconomic characteristics: CROYDON.

\begin{tabular}{|c|c|c|c|c|}
\hline & & Number & Inside LTN & Within $500 \mathrm{~m}$ of a modal filter \\
\hline All & & 363,378 & $3.9 \%$ & $12.6 \%$ \\
\hline \multirow[t]{4}{*}{ Age } & 0 to 4 & 27,972 & $4.6 \%$ & $15.0 \%$ \\
\hline & 5 to 17 & 61,072 & $4.0 \%$ & $12.3 \%$ \\
\hline & 18 to 64 & 229,959 & $3.9 \%$ & $13.1 \%$ \\
\hline & $65+$ & 44,375 & $3.0 \%$ & $8.7 \%$ \\
\hline \multirow[t]{4}{*}{ Ethnicity } & White & 199,961 & $3.0 \%$ & $9.5 \%$ \\
\hline & Black & 73,256 & $6.2 \%$ & $18.7 \%$ \\
\hline & Asian & 59,627 & $3.5 \%$ & $13.8 \%$ \\
\hline & Mixed or other & 30,534 & $4.8 \%$ & $15.7 \%$ \\
\hline \multirow[t]{3}{*}{ Disability } & Not disabled & 310,265 & $3.9 \%$ & $12.7 \%$ \\
\hline & Limited a little & 28,733 & $3.8 \%$ & $11.5 \%$ \\
\hline & Limited a lot & 24,380 & $4.0 \%$ & $12.3 \%$ \\
\hline Household car & None & 48,523 & $5.8 \%$ & $18.4 \%$ \\
\hline ownership & 1 or more cars & 96,487 & $3.5 \%$ & $10.9 \%$ \\
\hline Household & Any employed adult & 103,494 & $4.1 \%$ & $13.5 \%$ \\
\hline employment & No employed adult & 41,516 & $4.5 \%$ & $13.2 \%$ \\
\hline Area & Quarter 1 (least deprived) & 81,098 & $0.0 \%$ & $1.6 \%$ \\
\hline \multirow[t]{3}{*}{ deprivation } & Quarter 2 & 84,447 & $1.7 \%$ & $8.5 \%$ \\
\hline & Quarter 3 & 100,567 & $6.8 \%$ & $19.8 \%$ \\
\hline & Quarter 4 (most deprived) & 97,266 & $6.1 \%$ & $17.8 \%$ \\
\hline
\end{tabular}

See notes to Table A4. 
Table A5.6: Proportion of Londoners living near different types of modal filter interventions, by demographic and socioeconomic characteristics: EALING.

\begin{tabular}{|c|c|c|c|c|}
\hline & & Number & Inside LTN & Within $500 \mathrm{~m}$ of a modal filter \\
\hline All & & 338,449 & $9.4 \%$ & $16.1 \%$ \\
\hline \multirow[t]{4}{*}{ Age } & 0 to 4 & 25,426 & $9.4 \%$ & $16.3 \%$ \\
\hline & 5 to 17 & 51,179 & $8.2 \%$ & $14.0 \%$ \\
\hline & 18 to 64 & 225,617 & $9.6 \%$ & $16.7 \%$ \\
\hline & $65+$ & 36,227 & $9.5 \%$ & $15.4 \%$ \\
\hline \multirow[t]{4}{*}{ Ethnicity } & White & 165,518 & $13.3 \%$ & $21.9 \%$ \\
\hline & Black & 36,860 & $6.7 \%$ & $12.6 \%$ \\
\hline & Asian & 100,439 & $4.4 \%$ & $8.2 \%$ \\
\hline & Mixed or other & 35,632 & $8.0 \%$ & $14.9 \%$ \\
\hline \multirow[t]{3}{*}{ Disability } & Not disabled & 290,670 & $9.5 \%$ & $16.4 \%$ \\
\hline & Limited a little & 24,894 & $8.5 \%$ & $14.6 \%$ \\
\hline & Limited a lot & 22,885 & $8.7 \%$ & $14.0 \%$ \\
\hline Household car & None & 43,847 & $10.5 \%$ & $19.1 \%$ \\
\hline ownership & 1 or more cars & 80,235 & $10.2 \%$ & $17.2 \%$ \\
\hline Household & Any employed adult & 91,191 & $10.6 \%$ & $18.3 \%$ \\
\hline employment & No employed adult & 32,891 & $9.4 \%$ & $16.6 \%$ \\
\hline Area & Quarter 1 (least deprived) & 50,400 & $23.7 \%$ & $34.3 \%$ \\
\hline \multirow[t]{3}{*}{ deprivation } & Quarter 2 & 100,256 & $9.6 \%$ & $14.7 \%$ \\
\hline & Quarter 3 & 108,055 & $3.4 \%$ & $11.4 \%$ \\
\hline & Quarter 4 (most deprived) & 79,738 & $8.2 \%$ & $12.9 \%$ \\
\hline
\end{tabular}

See notes to Table A4.

Table A5.7: Proportion of Londoners living near different types of modal filter interventions, by demographic and socioeconomic characteristics: ENFIELD.

\begin{tabular}{|c|c|c|c|c|}
\hline & & Number & Inside LTN & Within $500 \mathrm{~m}$ of a modal filter \\
\hline All & & 312,466 & $3.8 \%$ & $5.9 \%$ \\
\hline \multirow[t]{4}{*}{ Age } & 0 to 4 & 24,513 & $3.0 \%$ & $4.6 \%$ \\
\hline & 5 to 17 & 54,035 & $2.9 \%$ & $4.3 \%$ \\
\hline & 18 to 64 & 195,085 & $4.1 \%$ & $6.5 \%$ \\
\hline & $65+$ & 38,833 & $3.9 \%$ & $5.6 \%$ \\
\hline \multirow[t]{4}{*}{ Ethnicity } & White & 190,296 & $4.4 \%$ & $6.8 \%$ \\
\hline & Black & 53,687 & $1.2 \%$ & $2.3 \%$ \\
\hline & Asian & 34,893 & $4.8 \%$ & $6.6 \%$ \\
\hline & Mixed or other & 33,590 & $3.4 \%$ & $5.7 \%$ \\
\hline \multirow[t]{3}{*}{ Disability } & Not disabled & 264,487 & $3.9 \%$ & $6.0 \%$ \\
\hline & Limited a little & 25,297 & $3.3 \%$ & $5.2 \%$ \\
\hline & Limited a lot & 22,682 & $3.3 \%$ & $4.9 \%$ \\
\hline Household car & None & 38,933 & $3.2 \%$ & $5.8 \%$ \\
\hline ownership & 1 or more cars & 80,983 & $4.2 \%$ & $6.2 \%$ \\
\hline Household & Any employed adult & 81,155 & $4.4 \%$ & $7.0 \%$ \\
\hline employment & No employed adult & 38,761 & $2.7 \%$ & $4.2 \%$ \\
\hline Area & Quarter 1 (least deprived) & 57,229 & $12.1 \%$ & $14.4 \%$ \\
\hline \multirow[t]{3}{*}{ deprivation } & Quarter 2 & 61,355 & $7.4 \%$ & $13.4 \%$ \\
\hline & Quarter 3 & 67,309 & $0.6 \%$ & $2.9 \%$ \\
\hline & Quarter 4 (most deprived) & 126,573 & $0.0 \%$ & $0.0 \%$ \\
\hline
\end{tabular}

See notes to Table A4.

Table A5.8: Proportion of Londoners living near different types of modal filter interventions, by demographic and socioeconomic characteristics: GREENWICH.

\begin{tabular}{|c|c|c|c|c|}
\hline & & Number & Inside LTN & Within $500 \mathrm{~m}$ of a modal filter \\
\hline All & & 254,557 & $0.8 \%$ & $7.1 \%$ \\
\hline \multirow[t]{4}{*}{ Age } & 0 to 4 & 20,945 & $0.8 \%$ & $6.5 \%$ \\
\hline & 5 to 17 & 40,427 & $0.6 \%$ & $5.3 \%$ \\
\hline & 18 to 64 & 167,069 & $0.9 \%$ & $7.5 \%$ \\
\hline & $65+$ & 26,116 & $1.2 \%$ & $7.4 \%$ \\
\hline \multirow[t]{4}{*}{ Ethnicity } & White & 158,572 & $1.1 \%$ & $8.7 \%$ \\
\hline & Black & 48,655 & $0.3 \%$ & $3.6 \%$ \\
\hline & Asian & 29,894 & $0.3 \%$ & $4.6 \%$ \\
\hline & Mixed or other & 17,436 & $0.7 \%$ & $7.1 \%$ \\
\hline \multirow[t]{3}{*}{ Disability } & Not disabled & 216,123 & $0.9 \%$ & $7.2 \%$ \\
\hline & Limited a little & 19,417 & $0.7 \%$ & $6.4 \%$ \\
\hline & Limited a lot & 19,017 & $0.6 \%$ & $6.2 \%$ \\
\hline Household car & None & 42,455 & $0.8 \%$ & $8.4 \%$ \\
\hline ownership & 1 or more cars & 58,590 & $1.1 \%$ & $7.5 \%$ \\
\hline Household & Any employed adult & 70,369 & $1.1 \%$ & $8.4 \%$ \\
\hline employment & No employed adult & 30,676 & $0.8 \%$ & $6.9 \%$ \\
\hline Area & Quarter 1 (least deprived) & 24,317 & $5.5 \%$ & $17.0 \%$ \\
\hline \multirow[t]{3}{*}{ deprivation } & Quarter 2 & 68,610 & $0.4 \%$ & $7.2 \%$ \\
\hline & Quarter 3 & 82,181 & $0.6 \%$ & $7.7 \%$ \\
\hline & Quarter 4 (most deprived) & 79,449 & $0.0 \%$ & $3.3 \%$ \\
\hline
\end{tabular}

See notes to Table A4. 
Table A5.9: Proportion of Londoners living near different types of modal filter interventions, by demographic and socioeconomic characteristics: HACKNEY.

\begin{tabular}{|c|c|c|c|c|}
\hline & & Number & Inside LTN & Within $500 \mathrm{~m}$ of a modal filter \\
\hline All & & 246,270 & $17.5 \%$ & $37.7 \%$ \\
\hline \multirow[t]{4}{*}{ Age } & 0 to 4 & 19,149 & $15.4 \%$ & $33.0 \%$ \\
\hline & 5 to 17 & 37,246 & $16.5 \%$ & $33.3 \%$ \\
\hline & 18 to 64 & 172,480 & $17.8 \%$ & $39.3 \%$ \\
\hline & $65+$ & 17,395 & $18.6 \%$ & $37.1 \%$ \\
\hline \multirow[t]{4}{*}{ Ethnicity } & White & 134,143 & $16.1 \%$ & $36.7 \%$ \\
\hline & Black & 56,858 & $20.9 \%$ & $40.2 \%$ \\
\hline & Asian & 25,867 & $18.0 \%$ & $38.9 \%$ \\
\hline & Mixed or other & 29,402 & $16.6 \%$ & $36.6 \%$ \\
\hline \multirow[t]{3}{*}{ Disability } & Not disabled & 210,586 & $17.2 \%$ & $37.8 \%$ \\
\hline & Limited a little & 17,620 & $18.8 \%$ & $37.8 \%$ \\
\hline & Limited a lot & 18,064 & $18.9 \%$ & $37.3 \%$ \\
\hline Household car & None & 65,721 & $17.8 \%$ & $39.8 \%$ \\
\hline ownership & 1 or more cars & 35,969 & $18.3 \%$ & $38.4 \%$ \\
\hline Household & Any employed adult & 71,763 & $17.6 \%$ & $39.7 \%$ \\
\hline employment & No employed adult & 29,927 & $19.0 \%$ & $38.4 \%$ \\
\hline Area & Quarter 1 (least deprived) & 0 & & \\
\hline \multirow[t]{3}{*}{ deprivation } & Quarter 2 & 13,304 & $0.0 \%$ & $28.5 \%$ \\
\hline & Quarter 3 & 75,095 & $17.8 \%$ & $35.1 \%$ \\
\hline & Quarter 4 (most deprived) & 157,871 & $18.8 \%$ & $39.7 \%$ \\
\hline
\end{tabular}

See notes to Table A4.

Table A5.10: Proportion of Londoners living near different types of modal filter interventions, by demographic and socioeconomic characteristics: HAMMERSMITH \& FULHAM.

\begin{tabular}{|c|c|c|c|c|}
\hline & & Number & Inside LTN & Within $500 \mathrm{~m}$ of a modal filter \\
\hline All & & 182,493 & $3.2 \%$ & $7.6 \%$ \\
\hline \multirow[t]{4}{*}{ Age } & 0 to 4 & 11,900 & $3.1 \%$ & $8.2 \%$ \\
\hline & 5 to 17 & 20,613 & $3.0 \%$ & $8.1 \%$ \\
\hline & 18 to 64 & 133,567 & $3.3 \%$ & $7.6 \%$ \\
\hline & $65+$ & 16,413 & $3.4 \%$ & $7.3 \%$ \\
\hline \multirow[t]{4}{*}{ Ethnicity } & White & 124,005 & $3.6 \%$ & $8.4 \%$ \\
\hline & Black & 21,505 & $2.5 \%$ & $5.4 \%$ \\
\hline & Asian & 16,635 & $2.4 \%$ & $6.3 \%$ \\
\hline & Mixed or other & 20,348 & $2.6 \%$ & $6.2 \%$ \\
\hline \multirow[t]{3}{*}{ Disability } & Not disabled & 159,535 & $3.2 \%$ & $7.7 \%$ \\
\hline & Limited a little & 11,485 & $3.2 \%$ & $6.8 \%$ \\
\hline & Limited a lot & 11,473 & $3.4 \%$ & $6.9 \%$ \\
\hline Household car & None & 44,524 & $2.8 \%$ & $6.3 \%$ \\
\hline ownership & 1 or more cars & 36,066 & $3.8 \%$ & $8.6 \%$ \\
\hline Household & Any employed adult & 59,398 & $3.3 \%$ & $7.4 \%$ \\
\hline employment & No employed adult & 21,192 & $3.1 \%$ & $7.0 \%$ \\
\hline Area & Quarter 1 (least deprived) & 31,180 & $0.5 \%$ & $7.2 \%$ \\
\hline \multirow[t]{3}{*}{ deprivation } & Quarter 2 & 57,344 & $5.5 \%$ & $12.2 \%$ \\
\hline & Quarter 3 & 44,999 & $5.8 \%$ & $7.5 \%$ \\
\hline & Quarter 4 (most deprived) & 48,970 & $0.0 \%$ & $2.7 \%$ \\
\hline
\end{tabular}

See notes to Table A4.

Table A5.11: Proportion of Londoners living near different types of modal filter interventions, by demographic and socioeconomic characteristics: HARROW.

\begin{tabular}{|c|c|c|c|c|}
\hline & & Number & Inside LTN & Within $500 \mathrm{~m}$ of a modal filter \\
\hline All & & 239,056 & $2.0 \%$ & $3.4 \%$ \\
\hline \multirow[t]{4}{*}{ Age } & 0 to 4 & 15,916 & $2.0 \%$ & $3.4 \%$ \\
\hline & 5 to 17 & 38,746 & $1.9 \%$ & $3.2 \%$ \\
\hline & 18 to 64 & 150,727 & $2.2 \%$ & $3.5 \%$ \\
\hline & $65+$ & 33,667 & $1.7 \%$ & $3.1 \%$ \\
\hline \multirow[t]{4}{*}{ Ethnicity } & White & 100,810 & $2.0 \%$ & $3.7 \%$ \\
\hline & Black & 19,708 & $2.4 \%$ & $3.4 \%$ \\
\hline & Asian & 101,808 & $2.0 \%$ & $3.0 \%$ \\
\hline & Mixed or other & 16,730 & $2.4 \%$ & $3.6 \%$ \\
\hline \multirow[t]{3}{*}{ Disability } & Not disabled & 204,202 & $2.1 \%$ & $3.4 \%$ \\
\hline & Limited a little & 18,687 & $1.9 \%$ & $3.4 \%$ \\
\hline & Limited a lot & 16,167 & $2.0 \%$ & $3.2 \%$ \\
\hline Household car & None & 19,811 & $2.5 \%$ & $3.6 \%$ \\
\hline ownership & 1 or more cars & 64,457 & $1.9 \%$ & $3.4 \%$ \\
\hline Household & Any employed adult & 61,805 & $2.1 \%$ & $3.5 \%$ \\
\hline employment & No employed adult & 22,463 & $1.9 \%$ & $3.3 \%$ \\
\hline Area & Quarter 1 (least deprived) & 86,999 & $1.8 \%$ & $5.1 \%$ \\
\hline \multirow[t]{3}{*}{ deprivation } & Quarter 2 & 115,259 & $1.4 \%$ & $1.8 \%$ \\
\hline & Quarter 3 & 25,639 & $6.5 \%$ & $6.3 \%$ \\
\hline & Quarter 4 (most deprived) & 11,159 & $0.0 \%$ & $0.0 \%$ \\
\hline
\end{tabular}

See notes to Table A4. 
Table A5.12: Proportion of Londoners living near different types of modal filter interventions, by demographic and socioeconomic characteristics: HOUNSLOW.

\begin{tabular}{|c|c|c|c|c|}
\hline & & Number & Inside LTN & Within $500 \mathrm{~m}$ of a modal filter \\
\hline All & & 253,957 & $6.2 \%$ & $12.5 \%$ \\
\hline \multirow[t]{4}{*}{ Age } & 0 to 4 & 19,725 & $6.2 \%$ & $12.4 \%$ \\
\hline & 5 to 17 & 37,762 & $6.0 \%$ & $11.2 \%$ \\
\hline & 18 to 64 & 169,611 & $6.1 \%$ & $12.8 \%$ \\
\hline & $65+$ & 26,859 & $6.6 \%$ & $12.6 \%$ \\
\hline \multirow[t]{4}{*}{ Ethnicity } & White & 130,322 & $8.8 \%$ & $17.5 \%$ \\
\hline & Black & 16,813 & $6.9 \%$ & $13.8 \%$ \\
\hline & Asian & 87,257 & $1.9 \%$ & $4.7 \%$ \\
\hline & Mixed or other & 19,565 & $6.9 \%$ & $13.5 \%$ \\
\hline \multirow[t]{3}{*}{ Disability } & Not disabled & 218,954 & $6.1 \%$ & $12.6 \%$ \\
\hline & Limited a little & 18,600 & $6.1 \%$ & $11.8 \%$ \\
\hline & Limited a lot & 16,403 & $6.4 \%$ & $11.9 \%$ \\
\hline Household car & None & 29,985 & $8.0 \%$ & $16.6 \%$ \\
\hline ownership & 1 or more cars & 64,917 & $6.6 \%$ & $13.7 \%$ \\
\hline Household & Any employed adult & 70,529 & $6.8 \%$ & $14.6 \%$ \\
\hline employment & No employed adult & 24,373 & $7.6 \%$ & $14.5 \%$ \\
\hline Area & Quarter 1 (least deprived) & 30,451 & $18.5 \%$ & $35.1 \%$ \\
\hline \multirow[t]{3}{*}{ deprivation } & Quarter 2 & 95,067 & $1.8 \%$ & $8.6 \%$ \\
\hline & Quarter 3 & 91,286 & $3.5 \%$ & $5.7 \%$ \\
\hline & Quarter 4 (most deprived) & 37,153 & $13.6 \%$ & $20.9 \%$ \\
\hline
\end{tabular}

See notes to Table A4.

Table A5.13: Proportion of Londoners living near different types of modal filter interventions, by demographic and socioeconomic characteristics: ISLINGTON.

\begin{tabular}{|c|c|c|c|c|}
\hline & & Number & Inside LTN & Within $500 \mathrm{~m}$ of a modal filter \\
\hline All & & 206,125 & $8.6 \%$ & $22.1 \%$ \\
\hline \multirow[t]{4}{*}{ Age } & 0 to 4 & 12,289 & $8.2 \%$ & $20.6 \%$ \\
\hline & 5 to 17 & 24,096 & $8.1 \%$ & $20.1 \%$ \\
\hline & 18 to 64 & 151,704 & $8.5 \%$ & $22.5 \%$ \\
\hline & $65+$ & 18,036 & $9.9 \%$ & $22.2 \%$ \\
\hline \multirow[t]{4}{*}{ Ethnicity } & White & 140,352 & $9.4 \%$ & $22.7 \%$ \\
\hline & Black & 26,294 & $6.6 \%$ & $18.4 \%$ \\
\hline & Asian & 19,034 & $6.4 \%$ & $24.0 \%$ \\
\hline & Mixed or other & 20,445 & $7.7 \%$ & $20.6 \%$ \\
\hline \multirow[t]{3}{*}{ Disability } & Not disabled & 173,854 & $8.5 \%$ & $22.2 \%$ \\
\hline & Limited a little & 15,729 & $9.1 \%$ & $21.9 \%$ \\
\hline & Limited a lot & 16,542 & $8.7 \%$ & $20.9 \%$ \\
\hline Household car & None & 60,485 & $8.8 \%$ & $23.9 \%$ \\
\hline ownership & 1 or more cars & 33,071 & $9.6 \%$ & $20.9 \%$ \\
\hline Household & Any employed adult & 65,311 & $9.1 \%$ & $22.6 \%$ \\
\hline employment & No employed adult & 28,245 & $9.0 \%$ & $23.5 \%$ \\
\hline Area & Quarter 1 (least deprived) & 2527 & $0.0 \%$ & $0.0 \%$ \\
\hline \multirow[t]{3}{*}{ deprivation } & Quarter 2 & 47,646 & $7.6 \%$ & $20.1 \%$ \\
\hline & Quarter 3 & 72,881 & $11.2 \%$ & $31.1 \%$ \\
\hline & Quarter 4 (most deprived) & 83,071 & $7.1 \%$ & $16.0 \%$ \\
\hline
\end{tabular}

See notes to Table A4

Table A5.14: Proportion of Londoners living near different types of modal filter interventions, by demographic and socioeconomic characteristics: KINGSTON UPON THAMES.

\begin{tabular}{|c|c|c|c|c|}
\hline & & Number & Inside LTN & Within $500 \mathrm{~m}$ of a modal filter \\
\hline All & & 160,060 & $0 \%$ & $4.9 \%$ \\
\hline \multirow[t]{4}{*}{ Age } & 0 to 4 & 10,964 & $0 \%$ & $5.4 \%$ \\
\hline & 5 to 17 & 22,728 & $0 \%$ & $3.9 \%$ \\
\hline & 18 to 64 & 106,010 & $0 \%$ & $5.1 \%$ \\
\hline & $65+$ & 20,358 & $0 \%$ & $4.5 \%$ \\
\hline \multirow[t]{4}{*}{ Ethnicity } & White & 119,124 & $0 \%$ & $5.3 \%$ \\
\hline & Black & 4021 & $0 \%$ & $5.1 \%$ \\
\hline & Asian & 26,152 & $0 \%$ & $2.8 \%$ \\
\hline & Mixed or other & 10,763 & $0 \%$ & $4.9 \%$ \\
\hline \multirow[t]{3}{*}{ Disability } & Not disabled & 140,158 & $0 \%$ & $4.9 \%$ \\
\hline & Limited a little & 11,297 & $0 \%$ & $4.6 \%$ \\
\hline & Limited a lot & 8605 & $0 \%$ & $5.0 \%$ \\
\hline Household car & None & 15,997 & $0 \%$ & $6.4 \%$ \\
\hline ownership & 1 or more cars & 47,642 & $0 \%$ & $5.0 \%$ \\
\hline Household & Any employed adult & 47,199 & $0 \%$ & $5.4 \%$ \\
\hline employment & No employed adult & 16,440 & $0 \%$ & $5.0 \%$ \\
\hline Area & Quarter 1 (least deprived) & 99,809 & $0 \%$ & $5.9 \%$ \\
\hline \multirow[t]{3}{*}{ deprivation } & Quarter 2 & 52,228 & $0 \%$ & $2.7 \%$ \\
\hline & Quarter 3 & 4705 & $0 \%$ & $0.0 \%$ \\
\hline & Quarter 4 (most deprived) & 3318 & $0 \%$ & $16.2 \%$ \\
\hline
\end{tabular}


See notes to Table A4.

Table A5.15: Proportion of Londoners living near different types of modal filter interventions, by demographic and socioeconomic characteristics: LAMBETH.

\begin{tabular}{|c|c|c|c|c|}
\hline & & Number & Inside LTN & Within $500 \mathrm{~m}$ of a modal filter \\
\hline All & & 303,086 & $15.0 \%$ & $24.9 \%$ \\
\hline \multirow[t]{4}{*}{ Age } & 0 to 4 & 20,701 & $13.6 \%$ & $21.6 \%$ \\
\hline & 5 to 17 & 39,661 & $14.3 \%$ & $23.4 \%$ \\
\hline & 18 to 64 & 219,537 & $15.3 \%$ & $25.7 \%$ \\
\hline & $65+$ & 23,187 & $14.5 \%$ & $22.9 \%$ \\
\hline \multirow[t]{4}{*}{ Ethnicity } & White & 172,830 & $14.9 \%$ & $25.0 \%$ \\
\hline & Black & 78,542 & $15.7 \%$ & $25.9 \%$ \\
\hline & Asian & 20,938 & $11.9 \%$ & $19.8 \%$ \\
\hline & Mixed or other & 30,776 & $15.4 \%$ & $25.3 \%$ \\
\hline \multirow[t]{3}{*}{ Disability } & Not disabled & 264,415 & $15.0 \%$ & $25.0 \%$ \\
\hline & Limited a little & 20,053 & $14.5 \%$ & $24.3 \%$ \\
\hline & Limited a lot & 18,618 & $15.0 \%$ & $24.6 \%$ \\
\hline Household car & None & 75,214 & $15.7 \%$ & $27.5 \%$ \\
\hline ownership & 1 or more cars & 54.803 & $14.2 \%$ & $22.2 \%$ \\
\hline Household & Any employed adult & 97.219 & $15.2 \%$ & $25.6 \%$ \\
\hline employment & No employed adult & 32.798 & $14.6 \%$ & $24.4 \%$ \\
\hline Area & Quarter 1 (least deprived) & 9.767 & $0.0 \%$ & $0.0 \%$ \\
\hline \multirow[t]{3}{*}{ deprivation } & Quarter 2 & 79.168 & $9.7 \%$ & $15.2 \%$ \\
\hline & Quarter 3 & 114.811 & $18.3 \%$ & $29.7 \%$ \\
\hline & Quarter 4 (most deprived) & 99.340 & $16.8 \%$ & $29.5 \%$ \\
\hline
\end{tabular}

See notes to Table A4.

Table A5.16: Proportion of Londoners living near different types of modal filter interventions, by demographic and socioeconomic characteristics: LEWISHAM.

\begin{tabular}{|c|c|c|c|c|}
\hline & & Number & Inside LTN & Within $500 \mathrm{~m}$ of a modal filter \\
\hline All & & 275.885 & $5.2 \%$ & $13.3 \%$ \\
\hline \multirow[t]{4}{*}{ Age } & 0 to 4 & 22.004 & $5.1 \%$ & $12.6 \%$ \\
\hline & 5 to 17 & 41.503 & $4.5 \%$ & $11.8 \%$ \\
\hline & 18 to 64 & 186.243 & $5.2 \%$ & $13.7 \%$ \\
\hline & $65+$ & 26.135 & $6.1 \%$ & $13.2 \%$ \\
\hline \multirow[t]{4}{*}{ Ethnicity } & White & 147.478 & $6.4 \%$ & $15.0 \%$ \\
\hline & Black & 74.942 & $3.1 \%$ & $10.3 \%$ \\
\hline & Asian & 25.534 & $5.4 \%$ & $13.6 \%$ \\
\hline & Mixed or other & 27.931 & $4.3 \%$ & $12.1 \%$ \\
\hline \multirow[t]{3}{*}{ Disability } & Not disabled & 236.150 & $5.2 \%$ & $13.4 \%$ \\
\hline & Limited a little & 20.212 & $5.2 \%$ & $13.4 \%$ \\
\hline & Limited a lot & 19.523 & $4.9 \%$ & $12.4 \%$ \\
\hline Household car & None & 55.893 & $4.6 \%$ & $13.3 \%$ \\
\hline ownership & 1 or more cars & 60.198 & $6.0 \%$ & $14.0 \%$ \\
\hline Household & Any employed adult & 83.529 & $5.5 \%$ & $14.1 \%$ \\
\hline employment & No employed adult & 32.562 & $4.9 \%$ & $12.6 \%$ \\
\hline Area & Quarter 1 (least deprived) & 13.188 & $14.2 \%$ & $20.1 \%$ \\
\hline \multirow[t]{3}{*}{ deprivation } & Quarter 2 & 58.070 & $10.8 \%$ & $17.0 \%$ \\
\hline & Quarter 3 & 98.979 & $3.3 \%$ & $13.1 \%$ \\
\hline & Quarter 4 (most deprived) & 105.648 & $2.9 \%$ & $10.6 \%$ \\
\hline
\end{tabular}

See notes to Table A4.

Table A5.17: Proportion of Londoners living near different types of modal filter interventions, by demographic and socioeconomic characteristics: MERTON.

\begin{tabular}{|c|c|c|c|c|}
\hline & & Number & Inside LTN & Within $500 \mathrm{~m}$ of a modal filter \\
\hline All & & 199.693 & $1.7 \%$ & $4.0 \%$ \\
\hline \multirow[t]{4}{*}{ Age } & 0 to 4 & 14.830 & $1.6 \%$ & $4.1 \%$ \\
\hline & 5 to 17 & 28.441 & $1.6 \%$ & $4.4 \%$ \\
\hline & 18 to 64 & 133.300 & $1.7 \%$ & $4.1 \%$ \\
\hline & $65+$ & 23.122 & $1.7 \%$ & $3.4 \%$ \\
\hline \multirow[t]{4}{*}{ Ethnicity } & White & 129.390 & $1.1 \%$ & $2.6 \%$ \\
\hline & Black & 20.811 & $3.0 \%$ & $7.9 \%$ \\
\hline & Asian & 36,143 & $3.0 \%$ & $6.8 \%$ \\
\hline & Mixed or other & 13,349 & $1.9 \%$ & $5.0 \%$ \\
\hline \multirow[t]{3}{*}{ Disability } & Not disabled & 174,461 & $1.7 \%$ & $4.0 \%$ \\
\hline & Limited a little & 13,993 & $2.1 \%$ & $4.4 \%$ \\
\hline & Limited a lot & 11,239 & $1.6 \%$ & $3.7 \%$ \\
\hline Household car & None & 25,644 & $1.6 \%$ & $3.7 \%$ \\
\hline ownership & 1 or more cars & 53,113 & $1.4 \%$ & $3.6 \%$ \\
\hline Household & Any employed adult & 59,940 & $1.5 \%$ & $3.7 \%$ \\
\hline employment & No employed adult & 18,817 & $1.4 \%$ & $3.4 \%$ \\
\hline Area & Quarter 1 (least deprived) & 97,795 & $1.3 \%$ & $1.6 \%$ \\
\hline \multirow[t]{3}{*}{ deprivation } & Quarter 2 & 53,596 & $3.1 \%$ & $8.5 \%$ \\
\hline & Quarter 3 & 34,456 & $0.5 \%$ & $2.8 \%$ \\
\hline & Quarter 4 (most deprived) & 13,846 & $2.1 \%$ & $7.1 \%$ \\
\hline
\end{tabular}

See notes to Table A4. 
Table A5.18: Proportion of Londoners living near different types of modal filter interventions, by demographic and socioeconomic characteristics: NEWHAM.

\begin{tabular}{|c|c|c|c|c|}
\hline & & Number & Inside LTN & Within $500 \mathrm{~m}$ of a modal filter \\
\hline All & & 307,984 & $4.2 \%$ & $6.4 \%$ \\
\hline \multirow[t]{4}{*}{ Age } & 0 to 4 & 25,384 & $3.6 \%$ & $5.6 \%$ \\
\hline & 5 to 17 & 52,444 & $4.0 \%$ & $5.8 \%$ \\
\hline & 18 to 64 & 209,563 & $4.3 \%$ & $6.6 \%$ \\
\hline & $65+$ & 20,593 & $4.7 \%$ & $6.8 \%$ \\
\hline \multirow[t]{4}{*}{ Ethnicity } & White & 88,754 & $5.1 \%$ & $7.8 \%$ \\
\hline & Black & 60,256 & $6.0 \%$ & $8.5 \%$ \\
\hline & Asian & 133,895 & $2.8 \%$ & $4.3 \%$ \\
\hline & Mixed or other & 25,079 & $4.6 \%$ & $7.4 \%$ \\
\hline \multirow[t]{3}{*}{ Disability } & Not disabled & 265,273 & $4.2 \%$ & $6.4 \%$ \\
\hline & Limited a little & 21,148 & $4.2 \%$ & $6.1 \%$ \\
\hline & Limited a lot & 21,563 & $4.2 \%$ & $6.3 \%$ \\
\hline Household car & None & 52,849 & $4.7 \%$ & $7.5 \%$ \\
\hline ownership & 1 or more cars & 48,670 & $4.3 \%$ & $6.4 \%$ \\
\hline Household & Any employed adult & 72,800 & $4.5 \%$ & $7.1 \%$ \\
\hline employment & No employed adult & 28,719 & $4.5 \%$ & $6.6 \%$ \\
\hline Area & Quarter 1 (least deprived) & 1522 & $0.0 \%$ & $0.0 \%$ \\
\hline \multirow[t]{3}{*}{ deprivation } & Quarter 2 & 10,808 & $0.0 \%$ & $0.0 \%$ \\
\hline & Quarter 3 & 160,820 & $6.4 \%$ & $10.1 \%$ \\
\hline & Quarter 4 (most deprived) & 134,834 & $2.0 \%$ & $2.6 \%$ \\
\hline
\end{tabular}

See notes to Table A4.

Table A5.19: Proportion of Londoners living near different types of modal filter interventions, by demographic and socioeconomic characteristics: SOUTHWARK.

\begin{tabular}{|c|c|c|c|c|}
\hline & & Number & Inside LTN & Within $500 \mathrm{~m}$ of a modal filter \\
\hline All & & 288,283 & $5.8 \%$ & $22.5 \%$ \\
\hline \multirow[t]{4}{*}{ Age } & 0 to 4 & 20,739 & $5.0 \%$ & $23.9 \%$ \\
\hline & 5 to 17 & 38,299 & $5.5 \%$ & $23.7 \%$ \\
\hline & 18 to 64 & 206,916 & $6.0 \%$ & $21.9 \%$ \\
\hline & $65+$ & 22,329 & $6.1 \%$ & $24.4 \%$ \\
\hline \multirow[t]{4}{*}{ Ethnicity } & White & 156,086 & $6.1 \%$ & $21.7 \%$ \\
\hline & Black & 77,511 & $5.4 \%$ & $25.2 \%$ \\
\hline & Asian & 27,192 & $5.5 \%$ & $19.2 \%$ \\
\hline & Mixed or other & 27,494 & $5.9 \%$ & $23.0 \%$ \\
\hline \multirow[t]{3}{*}{ Disability } & Not disabled & 249,303 & $5.8 \%$ & $22.3 \%$ \\
\hline & Limited a little & 20,002 & $6.5 \%$ & $23.9 \%$ \\
\hline & Limited a lot & 18,978 & $6.1 \%$ & $23.9 \%$ \\
\hline Household car & None & 70,312 & $6.8 \%$ & $23.2 \%$ \\
\hline ownership & 1 or more cars & 50,110 & $4.9 \%$ & $21.3 \%$ \\
\hline Household & Any employed adult & 88,351 & $5.9 \%$ & $22.0 \%$ \\
\hline employment & No employed adult & 32,071 & $6.4 \%$ & $23.7 \%$ \\
\hline Area & Quarter 1 (least deprived) & 27,316 & $0.6 \%$ & $16.0 \%$ \\
\hline \multirow[t]{3}{*}{ deprivation } & Quarter 2 & 56,187 & $3.0 \%$ & $22.6 \%$ \\
\hline & Quarter 3 & 89,818 & $6.1 \%$ & $20.5 \%$ \\
\hline & Quarter 4 (most deprived) & 114,962 & $8.3 \%$ & $25.6 \%$ \\
\hline
\end{tabular}

See notes to Table A4.

Table A5.20: Proportion of Londoners living near different types of modal filter interventions, by demographic and socioeconomic characteristics: SUTTON.

\begin{tabular}{|c|c|c|c|c|}
\hline & & Number & Inside LTN & Within $500 \mathrm{~m}$ of a modal filter \\
\hline All & & 190,146 & $1.7 \%$ & $10.2 \%$ \\
\hline \multirow[t]{4}{*}{ Age } & 0 to 4 & 12,750 & $1.6 \%$ & $11.0 \%$ \\
\hline & 5 to 17 & 30,335 & $1.5 \%$ & $10.0 \%$ \\
\hline & 18 to 64 & 119,828 & $1.6 \%$ & $10.4 \%$ \\
\hline & $65+$ & 27,233 & $2.4 \%$ & $9.2 \%$ \\
\hline \multirow[t]{4}{*}{ Ethnicity } & White & 149,256 & $1.7 \%$ & $10.5 \%$ \\
\hline & Black & 9120 & $1.7 \%$ & $8.4 \%$ \\
\hline & Asian & 22,035 & $1.4 \%$ & $9.2 \%$ \\
\hline & Mixed or other & 9735 & $1.9 \%$ & $9.8 \%$ \\
\hline \multirow[t]{3}{*}{ Disability } & Not disabled & 162,957 & $1.6 \%$ & $10.3 \%$ \\
\hline & Limited a little & 15,067 & $2.1 \%$ & $10.1 \%$ \\
\hline & Limited a lot & 12,122 & $2.1 \%$ & $9.0 \%$ \\
\hline Household car & None & 18,303 & $2.1 \%$ & $9.7 \%$ \\
\hline ownership & 1 or more cars & 59,871 & $1.7 \%$ & $10.3 \%$ \\
\hline Household & Any employed adult & 56,608 & $1.6 \%$ & $10.5 \%$ \\
\hline employment & No employed adult & 21,566 & $2.2 \%$ & $9.1 \%$ \\
\hline Area & Quarter 1 (least deprived) & 110,354 & $2.3 \%$ & $11.7 \%$ \\
\hline \multirow[t]{3}{*}{ deprivation } & Quarter 2 & 40,329 & $0.1 \%$ & $7.4 \%$ \\
\hline & Quarter 3 & 23,009 & $2.5 \%$ & $8.9 \%$ \\
\hline & Quarter 4 (most deprived) & 16,454 & $0.4 \%$ & $9.3 \%$ \\
\hline
\end{tabular}


See notes to Table A4

Table A5.21: Proportion of Londoners living near different types of modal filter interventions, by demographic and socioeconomic characteristics: TOWER HAMLETS.

\begin{tabular}{|c|c|c|c|c|}
\hline & & Number & Inside LTN & Within $500 \mathrm{~m}$ of a modal filter \\
\hline All & & 254,096 & $5.8 \%$ & $10.4 \%$ \\
\hline \multirow[t]{4}{*}{ Age } & 0 to 4 & 18,750 & $4.9 \%$ & $8.0 \%$ \\
\hline & 5 to 17 & 36,346 & $5.9 \%$ & $9.2 \%$ \\
\hline & 18 to 64 & 183,430 & $5.7 \%$ & $10.8 \%$ \\
\hline & $65+$ & 15,570 & $7.3 \%$ & $11.6 \%$ \\
\hline \multirow[t]{4}{*}{ Ethnicity } & White & 114,644 & $6.3 \%$ & $12.0 \%$ \\
\hline & Black & 18,629 & $5.4 \%$ & $9.2 \%$ \\
\hline & Asian & 104,501 & $5.3 \%$ & $8.7 \%$ \\
\hline & Mixed or other & 16,322 & $5.9 \%$ & $11.2 \%$ \\
\hline \multirow[t]{3}{*}{ Disability } & Not disabled & 219,793 & $5.6 \%$ & $10.3 \%$ \\
\hline & Limited a little & 17,045 & $6.6 \%$ & $11.0 \%$ \\
\hline & Limited a lot & 17,258 & $7.0 \%$ & $11.4 \%$ \\
\hline Household car & None & 63,797 & $6.3 \%$ & $12.3 \%$ \\
\hline ownership & 1 or more cars & 37,460 & $4.8 \%$ & $8.5 \%$ \\
\hline Household & Any employed adult & 73,934 & $5.4 \%$ & $10.8 \%$ \\
\hline employment & No employed adult & 27,323 & $6.6 \%$ & $11.1 \%$ \\
\hline Area & Quarter 1 (least deprived) & 16,725 & $0.0 \%$ & $0.0 \%$ \\
\hline \multirow[t]{3}{*}{ deprivation } & Quarter 2 & 32,856 & $0.0 \%$ & $5.0 \%$ \\
\hline & Quarter 3 & 80,328 & $6.1 \%$ & $12.6 \%$ \\
\hline & Quarter 4 (most deprived) & 124,187 & $7.9 \%$ & $11.8 \%$ \\
\hline
\end{tabular}

See notes to Table A4.

Table A5.22: Proportion of Londoners living near different types of modal filter interventions, by demographic and socioeconomic characteristics: WALTHAM FOREST.

\begin{tabular}{|c|c|c|c|c|}
\hline & & Number & Inside LTN & Within $500 \mathrm{~m}$ of a modal filter \\
\hline All & & 258,249 & $6.0 \%$ & $13.0 \%$ \\
\hline \multirow[t]{4}{*}{ Age } & 0 to 4 & 20,839 & $6.5 \%$ & $13.8 \%$ \\
\hline & 5 to 17 & 40,513 & $5.9 \%$ & $12.4 \%$ \\
\hline & 18 to 64 & 171,331 & $6.1 \%$ & $13.5 \%$ \\
\hline & $65+$ & 25,566 & $4.6 \%$ & $10.2 \%$ \\
\hline \multirow[t]{4}{*}{ Ethnicity } & White & 134,430 & $5.4 \%$ & $11.5 \%$ \\
\hline & Black & 44,791 & $6.6 \%$ & $14.4 \%$ \\
\hline & Asian & 54,389 & $6.8 \%$ & $15.5 \%$ \\
\hline & Mixed or other & 24,639 & $5.8 \%$ & $13.6 \%$ \\
\hline \multirow[t]{3}{*}{ Disability } & Not disabled & 220,621 & $6.0 \%$ & $13.1 \%$ \\
\hline & Limited a little & 19,744 & $6.0 \%$ & $12.6 \%$ \\
\hline & Limited a lot & 17,884 & $5.7 \%$ & $12.6 \%$ \\
\hline Household car & None & 40,583 & $6.7 \%$ & $15.7 \%$ \\
\hline ownership & 1 or more cars & 56,278 & $5.4 \%$ & $11.1 \%$ \\
\hline Household & Any employed adult & 69,582 & $6.2 \%$ & $13.5 \%$ \\
\hline employment & No employed adult & 27,279 & $5.2 \%$ & $11.9 \%$ \\
\hline Area & Quarter 1 (least deprived) & 8342 & $0.0 \%$ & $0.0 \%$ \\
\hline \multirow[t]{3}{*}{ deprivation } & Quarter 2 & 64,465 & $4.7 \%$ & $7.8 \%$ \\
\hline & Quarter 3 & 120,028 & $9.0 \%$ & $15.8 \%$ \\
\hline & Quarter 4 (most deprived) & 65,414 & $2.3 \%$ & $14.9 \%$ \\
\hline
\end{tabular}

See notes to Table A4.

Table A5.23: Proportion of Londoners living near different types of modal filter interventions, by demographic and socioeconomic characteristics: WESTMINSTER.

\begin{tabular}{|c|c|c|c|c|}
\hline & & Number & Inside LTN & Within $500 \mathrm{~m}$ of a modal filter \\
\hline All & & 219,396 & $1.8 \%$ & $14.9 \%$ \\
\hline \multirow[t]{4}{*}{ Age } & 0 to 4 & 12,617 & $0.9 \%$ & $11.4 \%$ \\
\hline & 5 to 17 & 23,341 & $0.9 \%$ & $9.1 \%$ \\
\hline & 18 to 64 & 158,924 & $2.0 \%$ & $16.2 \%$ \\
\hline & $65+$ & 24,514 & $1.7 \%$ & $14.0 \%$ \\
\hline \multirow[t]{4}{*}{ Ethnicity } & White & 135,254 & $1.9 \%$ & $15.8 \%$ \\
\hline & Black & 16,472 & $0.8 \%$ & $7.7 \%$ \\
\hline & Asian & 31,862 & $2.4 \%$ & $15.1 \%$ \\
\hline & Mixed or other & 35,808 & $1.1 \%$ & $14.6 \%$ \\
\hline \multirow[t]{3}{*}{ Disability } & Not disabled & 188,517 & $1.8 \%$ & $15.3 \%$ \\
\hline & Limited a little & 15,553 & $1.8 \%$ & $12.6 \%$ \\
\hline & Limited a lot & 15,326 & $1.6 \%$ & $11.9 \%$ \\
\hline Household car & None & 66,531 & $2.8 \%$ & $18.0 \%$ \\
\hline ownership & 1 or more cars & 39,241 & $1.0 \%$ & $13.5 \%$ \\
\hline Household & Any employed adult & 73,736 & $2.1 \%$ & $16.6 \%$ \\
\hline employment & No employed adult & 32,036 & $2.0 \%$ & $15.7 \%$ \\
\hline Area & Quarter 1 (least deprived) & 74,693 & $0.4 \%$ & $13.2 \%$ \\
\hline
\end{tabular}


(continued)

\begin{tabular}{|c|c|c|c|c|}
\hline & & Number & Inside LTN & Within $500 \mathrm{~m}$ of a modal filter \\
\hline \multirow[t]{3}{*}{ deprivation } & Quarter 2 & 46,664 & $0.4 \%$ & $28.6 \%$ \\
\hline & Quarter 3 & 45,504 & $3.4 \%$ & $10.5 \%$ \\
\hline & Quarter 4 (most deprived) & 52,535 & $3.6 \%$ & $9.0 \%$ \\
\hline
\end{tabular}

See notes to Table A4.

Appendix C. Comparisons of LTN implementation according to area deprivation and ethnicity, by district

Table A6: LTN implementation and other characteristics, by district.

\begin{tabular}{|c|c|c|c|c|c|c|c|}
\hline District & $\begin{array}{l}\text { \% Residents living } \\
\text { in new LTNs }\end{array}$ & $\begin{array}{l}\text { Population } \\
\text { (1000s) }\end{array}$ & $\begin{array}{l}\text { Inner } \\
\text { London? }\end{array}$ & $\begin{array}{l}\text { Mean district } \\
\text { deprivation } \\
\text { percentile }\end{array}$ & $\begin{array}{l}\% \text { BAME among } \\
\text { district residents }\end{array}$ & $\begin{array}{l}\text { \% disabled among } \\
\text { district residents }\end{array}$ & $\begin{array}{l}\text { No. cars per } \\
1000 \text { residents }\end{array}$ \\
\hline Barking and Dagenham & $0 \%$ & 186 & No & $80 \%$ & $42 \%$ & $16 \%$ & 306 \\
\hline Barnet & $0 \%$ & 356 & No & $35 \%$ & $36 \%$ & $14 \%$ & 406 \\
\hline Bexley & $0 \%$ & 232 & No & $35 \%$ & $18 \%$ & $16 \%$ & 468 \\
\hline Brent & $4 \%$ & 311 & No & $61 \%$ & $64 \%$ & $14 \%$ & 282 \\
\hline Bromley & $0 \%$ & 309 & No & $29 \%$ & $16 \%$ & $15 \%$ & 497 \\
\hline Camden & $4 \%$ & 220 & Yes & $47 \%$ & $34 \%$ & $14 \%$ & 211 \\
\hline City of London & $55 \%$ & 7 & Yes & $29 \%$ & $21 \%$ & $11 \%$ & 229 \\
\hline Croydon & $4 \%$ & 363 & No & $52 \%$ & $45 \%$ & $15 \%$ & 385 \\
\hline Ealing & $9 \%$ & 338 & No & $54 \%$ & $51 \%$ & $14 \%$ & 333 \\
\hline Enfield & $4 \%$ & 312 & No & $60 \%$ & $39 \%$ & $15 \%$ & 383 \\
\hline Greenwich & $1 \%$ & 255 & Yes & $59 \%$ & $38 \%$ & $15 \%$ & 307 \\
\hline Hackney & $17 \%$ & 246 & Yes & $79 \%$ & $46 \%$ & $14 \%$ & 170 \\
\hline Hammersmith \& Fulham & $3 \%$ & 182 & Yes & $53 \%$ & $32 \%$ & $13 \%$ & 240 \\
\hline Haringey & $0 \%$ & 255 & No & $65 \%$ & $40 \%$ & $14 \%$ & 241 \\
\hline Harrow & $2 \%$ & 239 & No & $33 \%$ & $58 \%$ & $15 \%$ & 420 \\
\hline Havering & $0 \%$ & 237 & No & $37 \%$ & $12 \%$ & $17 \%$ & 496 \\
\hline Hillingdon & $0 \%$ & 274 & No & $41 \%$ & $40 \%$ & $14 \%$ & 447 \\
\hline Hounslow & $6 \%$ & 254 & No & $51 \%$ & $49 \%$ & $14 \%$ & 370 \\
\hline Islington & $9 \%$ & 206 & Yes & $67 \%$ & $32 \%$ & $16 \%$ & 187 \\
\hline Kensington and Chelsea & $0 \%$ & 159 & Yes & $49 \%$ & $29 \%$ & $12 \%$ & 281 \\
\hline Kingston upon Thames & $0 \%$ & 160 & No & $22 \%$ & $26 \%$ & $12 \%$ & 440 \\
\hline Lambeth & $15 \%$ & 303 & Yes & $63 \%$ & $43 \%$ & $13 \%$ & 220 \\
\hline Lewisham & $5 \%$ & 276 & Yes & $65 \%$ & $47 \%$ & $14 \%$ & 277 \\
\hline Merton & $2 \%$ & 200 & No & $31 \%$ & $35 \%$ & $13 \%$ & 364 \\
\hline Newham & $4 \%$ & 308 & No & $73 \%$ & $71 \%$ & $14 \%$ & 198 \\
\hline Redbridge & $0 \%$ & 279 & No & $39 \%$ & $58 \%$ & $15 \%$ & 381 \\
\hline Richmond upon Thames & $0 \%$ & 187 & No & $16 \%$ & $14 \%$ & $11 \%$ & 454 \\
\hline Southwark & $6 \%$ & 288 & Yes & $63 \%$ & $46 \%$ & $14 \%$ & 210 \\
\hline Sutton & $2 \%$ & 190 & No & $29 \%$ & $22 \%$ & $14 \%$ & 480 \\
\hline Tower Hamlets & $6 \%$ & 254 & Yes & $69 \%$ & $55 \%$ & $14 \%$ & 172 \\
\hline Waltham Forest & $6 \%$ & 258 & No & $61 \%$ & $48 \%$ & $15 \%$ & 295 \\
\hline Wandsworth & $0 \%$ & 307 & Yes & $37 \%$ & $29 \%$ & $11 \%$ & 292 \\
\hline Westminster & $2 \%$ & 219 & Yes & $47 \%$ & $38 \%$ & $14 \%$ & 222 \\
\hline $\begin{array}{l}\text { Spearman correlation ( } p \text {-value) } \\
\text { with \% residents living in a new } \\
\text { LTN }\end{array}$ & - & $\begin{array}{l}0.15(p= \\
0.42)\end{array}$ & $\begin{array}{l}0.43(p= \\
0.01)\end{array}$ & $0.51(\mathrm{p}=0.003)$ & $0.45(\mathrm{p}=0.009)$ & $-0.11(p=0.53)$ & $\begin{array}{l}-0.66(\mathrm{p}< \\
0.001)\end{array}$ \\
\hline
\end{tabular}

BAME $=$ Black, Asian and Minority Ethnic. LTN $=$ low traffic neighbourhood. Deprivation percentiles are calculated by ranking each LSOA from 0 to 100 , with 100 corresponding to the highest level of deprivation.

Table A7: Equity analysis: proportion of residents inside an LTN, by ethnicity, small area deprivation and disability.

\begin{tabular}{|c|c|c|c|c|c|c|c|c|c|c|c|c|}
\hline & \multicolumn{4}{|c|}{ Ethnicity } & \multicolumn{4}{|c|}{ Deprivation: defined relative to London } & \multicolumn{4}{|l|}{ Disability } \\
\hline & $\begin{array}{l}\text { White } \\
\text { [A] }\end{array}$ & $\begin{array}{l}\text { BAME } \\
{[B]}\end{array}$ & $\begin{array}{l}\text { Difference } \\
{[\mathrm{B}]-[\mathrm{A}]}\end{array}$ & $\begin{array}{l}\text { Ratio } \\
{[\mathrm{B}] /} \\
{[\mathrm{A}]}\end{array}$ & $\begin{array}{l}\text { Least } \\
\text { deprived } \\
50 \%[C]\end{array}$ & $\begin{array}{l}\text { Most } \\
\text { deprived } \\
50 \% \text { [D] }\end{array}$ & $\begin{array}{l}\text { Difference } \\
{[D]-[C]}\end{array}$ & $\begin{array}{l}\text { Ratio } \\
{[\mathrm{D}] /} \\
{[\mathrm{C}]}\end{array}$ & $\begin{array}{l}\text { Not } \\
\text { disabled } \\
{[\mathrm{E}]}\end{array}$ & $\begin{array}{l}\text { Disabled } \\
{[\mathrm{F}]}\end{array}$ & $\begin{array}{l}\text { Difference } \\
{[\mathrm{F}]-[\mathrm{E}]}\end{array}$ & $\begin{array}{l}\text { Ratio } \\
{[\mathrm{F}] /} \\
{[\mathrm{E}]}\end{array}$ \\
\hline All London & $3.6 \%$ & $3.9 \%$ & $0.3 \%$ & 1.08 & $2.3 \%$ & $5.0 \%$ & $2.7 \%$ & 2.18 & $3.7 \%$ & $3.7 \%$ & $0.0 \%$ & 1.01 \\
\hline $\begin{array}{l}\text { All Inner } \\
\text { London }\end{array}$ & $6.0 \%$ & $6.2 \%$ & $0.2 \%$ & 1.03 & $3.1 \%$ & $7.9 \%$ & $4.8 \%$ & 2.54 & $6.0 \%$ & $6.4 \%$ & $0.4 \%$ & 1.07 \\
\hline $\begin{array}{l}\text { All Outer } \\
\text { London }\end{array}$ & $2.2 \%$ & $2.6 \%$ & $0.4 \%$ & 1.18 & $2.0 \%$ & $2.9 \%$ & $0.9 \%$ & 1.43 & $2.4 \%$ & $2.3 \%$ & $-0.1 \%$ & 0.96 \\
\hline Brent & $2.6 \%$ & $4.2 \%$ & $1.6 \%$ & 1.60 & $3.2 \%$ & $3.8 \%$ & $0.7 \%$ & 1.21 & $3.6 \%$ & $3.9 \%$ & $0.4 \%$ & 1.10 \\
\hline Camden & $4.7 \%$ & $3.4 \%$ & $-1.3 \%$ & 0.72 & $3.1 \%$ & $5.6 \%$ & $2.5 \%$ & 1.82 & $4.2 \%$ & $4.3 \%$ & $0.0 \%$ & 1.01 \\
\hline Croydon & $3.0 \%$ & $5.0 \%$ & $1.9 \%$ & 1.64 & $0.9 \%$ & $6.4 \%$ & $5.6 \%$ & 7.45 & $3.9 \%$ & $3.9 \%$ & $0.0 \%$ & 1.01 \\
\hline Ealing & $13.3 \%$ & $5.6 \%$ & $-7.7 \%$ & 0.42 & $14.4 \%$ & $5.4 \%$ & $-8.9 \%$ & 0.38 & $9.5 \%$ & $8.6 \%$ & $-0.9 \%$ & 0.90 \\
\hline Enfield & $4.4 \%$ & $2.8 \%$ & $-1.6 \%$ & 0.64 & $9.7 \%$ & $0.2 \%$ & $-9.4 \%$ & 0.02 & $3.9 \%$ & $3.3 \%$ & $-0.6 \%$ & 0.84 \\
\hline Greenwich & $1.1 \%$ & $0.3 \%$ & $-0.8 \%$ & 0.30 & $1.7 \%$ & $0.3 \%$ & $-1.4 \%$ & 0.19 & $0.9 \%$ & $0.6 \%$ & $-0.3 \%$ & 0.71 \\
\hline Hackney & $16.1 \%$ & $19.1 \%$ & $3.1 \%$ & 1.19 & $0.0 \%$ & $18.5 \%$ & $18.5 \%$ & Inf & $17.2 \%$ & $18.9 \%$ & $1.7 \%$ & 1.10 \\
\hline \multicolumn{13}{|l|}{ Hammersmith } \\
\hline \& Fulham & $3.6 \%$ & $2.5 \%$ & $-1.1 \%$ & 0.71 & $3.7 \%$ & $2.8 \%$ & $-0.9 \%$ & 0.75 & $3.2 \%$ & $3.3 \%$ & $0.1 \%$ & 1.02 \\
\hline & & & & & & & & & & & (continued & ext page) \\
\hline
\end{tabular}




\begin{tabular}{|c|c|c|c|c|c|c|c|c|c|c|c|c|}
\hline & \multicolumn{4}{|c|}{ Ethnicity } & \multicolumn{4}{|c|}{ Deprivation: defined relative to London } & \multicolumn{4}{|l|}{ Disability } \\
\hline & $\begin{array}{l}\text { White } \\
\text { [A] }\end{array}$ & $\begin{array}{l}\text { BAME } \\
{[\mathrm{B}]}\end{array}$ & $\begin{array}{l}\text { Difference } \\
{[\mathrm{B}]-[\mathrm{A}]}\end{array}$ & $\begin{array}{l}\text { Ratio } \\
{[\mathrm{B}] /} \\
{[\mathrm{A}]}\end{array}$ & $\begin{array}{l}\text { Least } \\
\text { deprived } \\
50 \%[\mathrm{C}]\end{array}$ & $\begin{array}{l}\text { Most } \\
\text { deprived } \\
50 \%[D]\end{array}$ & $\begin{array}{l}\text { Difference } \\
{[D]-[C]}\end{array}$ & $\begin{array}{l}\text { Ratio } \\
{[\mathrm{D}] /} \\
{[\mathrm{C}]}\end{array}$ & $\begin{array}{l}\text { Not } \\
\text { disabled } \\
{[\mathrm{E}]}\end{array}$ & $\begin{array}{l}\text { Disabled } \\
{[\mathrm{F}]}\end{array}$ & $\begin{array}{l}\text { Difference } \\
{[F]-[E]}\end{array}$ & $\begin{array}{l}\text { Ratio } \\
{[\mathrm{F}] /} \\
{[\mathrm{E}]}\end{array}$ \\
\hline Harrow & $2.0 \%$ & $2.1 \%$ & $0.2 \%$ & 1.08 & $1.6 \%$ & $4.5 \%$ & $2.9 \%$ & 2.82 & $2.1 \%$ & $2.0 \%$ & $-0.1 \%$ & 0.95 \\
\hline Hounslow & $8.8 \%$ & $3.4 \%$ & $-5.4 \%$ & 0.39 & $5.8 \%$ & $6.5 \%$ & $0.6 \%$ & 1.10 & $6.1 \%$ & $6.2 \%$ & $0.1 \%$ & 1.02 \\
\hline Islington & $9.4 \%$ & $6.9 \%$ & $-2.5 \%$ & 0.73 & $7.2 \%$ & $9.0 \%$ & $1.8 \%$ & 1.25 & $8.5 \%$ & $8.9 \%$ & $0.4 \%$ & 1.05 \\
\hline Lambeth & $14.9 \%$ & $15.0 \%$ & $0.0 \%$ & 1.00 & $8.7 \%$ & $17.6 \%$ & $8.9 \%$ & 2.03 & $15.0 \%$ & $14.8 \%$ & $-0.2 \%$ & 0.98 \\
\hline Lewisham & $6.4 \%$ & $3.8 \%$ & $-2.6 \%$ & 0.60 & $11.4 \%$ & $3.1 \%$ & $-8.3 \%$ & 0.27 & $5.2 \%$ & $5.0 \%$ & $-0.2 \%$ & 0.96 \\
\hline Merton & $1.1 \%$ & $2.8 \%$ & $1.7 \%$ & 2.61 & $1.9 \%$ & $1.0 \%$ & $-0.9 \%$ & 0.52 & $1.7 \%$ & $1.9 \%$ & $0.2 \%$ & 1.13 \\
\hline Newham & $5.1 \%$ & $3.9 \%$ & $-1.2 \%$ & 0.76 & $0.0 \%$ & $4.4 \%$ & $4.4 \%$ & Inf & $4.2 \%$ & $4.2 \%$ & $0.0 \%$ & 0.99 \\
\hline Southwark & $6.1 \%$ & $5.5 \%$ & $-0.6 \%$ & 0.90 & $2.2 \%$ & $7.3 \%$ & $5.1 \%$ & 3.30 & $5.8 \%$ & $6.3 \%$ & $0.5 \%$ & 1.09 \\
\hline Sutton & $1.7 \%$ & $1.6 \%$ & $-0.1 \%$ & 0.93 & $1.7 \%$ & $1.7 \%$ & $0.0 \%$ & 0.98 & $1.6 \%$ & $2.1 \%$ & $0.5 \%$ & 1.29 \\
\hline Tower Hamlets & $6.3 \%$ & $5.3 \%$ & $-0.9 \%$ & 0.86 & $0.0 \%$ & $7.2 \%$ & $7.2 \%$ & Inf & $5.6 \%$ & $6.8 \%$ & $1.2 \%$ & 1.22 \\
\hline Waltham Forest & $5.4 \%$ & $6.5 \%$ & $1.1 \%$ & 1.20 & $4.2 \%$ & $6.7 \%$ & $2.5 \%$ & 1.58 & $6.0 \%$ & $5.8 \%$ & $-0.2 \%$ & 0.97 \\
\hline Westminster & $1.9 \%$ & $1.5 \%$ & $-0.4 \%$ & 0.80 & $0.4 \%$ & $3.5 \%$ & $3.1 \%$ & 9.16 & $1.8 \%$ & $1.7 \%$ & $-0.1 \%$ & 0.97 \\
\hline District median & & & $-0.7 \%$ & 0.83 & & & $2.1 \%$ & 1.42 & & & $0.0 \%$ & 1.01 \\
\hline
\end{tabular}

BAME $=$ Black, Asian and Minority Ethnic. LTN = low traffic neighbourhood. Deprivation categorised relative to London as a whole. In 12 districts none of the population is covered by an LTN. These 12 districts are included in the All London/Inner London/Outer London analyses, but not presented separately in the districtlevel analysis. The City of London is also excluded from district-level analyses, as it is a very small district. Fig. 3 in the main report plots the 'Ratio' column for ethnicity against the 'Ratio' column for deprivation. Fig. 3 in the main report plots the 'Ratio' column for ethnicity against the 'Ratio' column for deprivation, i.e. most/least deprived $50 \%$ relative to the district in question. The 'district median' value at the bottom gives the median value for individual districts on the difference measures.

Table A8: Equity analysis: proportion of residents inside an LTN, by Asian vs White ethnicity.

\begin{tabular}{lllll}
\hline & Asian Ethnicity & & & \\
\cline { 2 - 5 } & White [A] & Asian [B] & Difference [B]-[A] & Ratio [B]/[A] \\
\hline All London & $3.6 \%$ & $2.9 \%$ & $-0.7 \%$ & 0.80 \\
All Inner London & $6.0 \%$ & $5.0 \%$ & $-1.0 \%$ & 0.84 \\
All Outer London & $2.2 \%$ & $2.2 \%$ & $-0.0 \%$ & 0.99 \\
Brent & $2.6 \%$ & $3.7 \%$ & $1.1 \%$ & 1.41 \\
Camden & $4.7 \%$ & $2.9 \%$ & $-1.8 \%$ & 0.61 \\
Croydon & $3.0 \%$ & $3.5 \%$ & $0.4 \%$ & 1.14 \\
Ealing & $13.3 \%$ & $4.4 \%$ & $-8.9 \%$ & 0.33 \\
Enfield & $4.4 \%$ & $4.8 \%$ & $0.3 \%$ & 1.07 \\
Greenwich & $1.1 \%$ & $0.3 \%$ & $0.9 \%$ \\
Hackney & $16.1 \%$ & $18.0 \%$ & $-1.0 \%$ & 1.12 \\
Hammersmith \& Fulham & $3.6 \%$ & $2.4 \%$ & $0.1 \%$ & 0.67 \\
Harrow & $2.0 \%$ & $2.0 \%$ & $-6.8 \%$ & 1.03 \\
Hounslow & $8.8 \%$ & $1.9 \%$ & $-3.0 \%$ & 0.22 \\
Islington & $9.4 \%$ & $6.4 \%$ & $-3.1 \%$ & 0.68 \\
Lambeth & $14.9 \%$ & $11.9 \%$ & $-1.0 \%$ & 0.79 \\
Lewisham & $6.4 \%$ & $5.4 \%$ & $2.0 \%$ & 0.85 \\
Merton & $1.1 \%$ & $3.0 \%$ & $-2.3 \%$ & 0.82 \\
Newham & $5.1 \%$ & $2.8 \%$ & $-0.6 \%$ & 0.91 \\
Southwark & $6.1 \%$ & $5.5 \%$ & $-0.3 \%$ & 0.83 \\
Sutton & $1.7 \%$ & $1.4 \%$ & $1.0 \%$ & 0.84 \\
Tower Hamlets & $6.3 \%$ & $5.3 \%$ & $0.5 \%$ & 1.26 \\
Waltham Forest & $5.4 \%$ & $6.8 \%$ & $-0.7 \%$ & 0.84 \\
Westminster & $1.9 \%$ & $2.4 \%$ & & \\
District median & & &
\end{tabular}

LTN = low traffic neighbourhood. In 12 districts none of the population is covered by an LTN. These 12 districts are included in the All London/Inner London/Outer London analyses, but not presented separately in the district-level analysis. The City of London is also excluded from district-level analyses, as it is a very small district.

\section{References}

Adkins, A., Makarewicz, C., Scanze, M., Ingram, M., Luhr, G., 2017. Contextualizing walkability: do relationships between built environments and walking vary by socioeconomic context? J. Am. Plan. Assoc. 83 (3), 296-314.

Aldred, R., 2018. Inequalities in self-report road injury risk in Britain: a new analysis of National Travel Survey data, focusing on pedestrian injuries. J. Transp. Health 9, 96-104.

Aldred, R. and Goodman, A., 2020. Low Traffic Neighbourhoods, car use, and active travel: evidence from the people and places survey of Outer London active travel interventions. Transp. Find. Doi:10.32866/001c.17128.

Aldred, R., Verlinghieri, E., 2020. LTNs for all? Mapping the Extent to London's New Low Traffic Neighbourhoods. Report for Possible, London.

Appleyard, D., 1969. The environmental quality of City streets: the residents viewpoint. J. Am. Plan. Assoc. 35, 84-101.

Barnes, J.H., Chatterton, T.J., Longhurst, J.W.S., 2019. Emissions vs exposure: increasing injustice from road traffic-related air pollution in the United Kingdom. Transp. Res. Part D: Transp. Environ. 73, 56-66. https://doi.org/10.1016/j.trd.2019.05.012.
Bartzokas-Tsiompras, A., Tampouraki, E.M., Photis, Y.N., 2020. Is walkability equally distributed among downtowners? Evaluating the pedestrian streetscapes of eight European capitals using a micro-scale audit approach. Int. J. Transp. Develop. Integr. 4 (1), 75-92.

Bostock, L., 2001. Pathways of disadvantage? Walking as a mode of transport among low-income mothers. Health Soc. Care Commun. 9, 11-18. https://doi.org/10.1046/ j.1365-2524.2001.00275.x.

Braun, L.M., Rodriguez, D.A., Gordon-Larsen, P., 2019. Social (in)equity in access to cycling infrastructure: cross-sectional associations between bike lanes and area-level sociodemographic characteristics in 22 large U.S. cities. J. Transp. Geogr. 80, 102544 https://doi.org/10.1016/j.jtrangeo.2019.102544.

Connolly, K., 2020. 'Cleaner and Greener': Covid-19 Prompts World's Cities to Free Public Space of Cars. The Guardian [Online]. [Accessed 16 December 2020]. Available from: http://www.theguardian.com/world/2020/may/18/cleaner-and-gr eener-covid-19-prompts-worlds-cities-to-free-public-space-of-cars.

Department for Transport, 2020. Road Traffic Statistics Region 6: London [Accessed 19 January 2021]. Available from: https://roadtraffic.dft.gov.uk/regions/6. 
Dunning, R., Nurse, A., 2020. Viewpoint the surprising availability of cycling and walking infrastructure through COVID-19. Town Plan. Rev. 92 (2), 149-155. https ://s3-eu-west-1.amazonaws.com/cp-cloudpublish-public/p6/5f64bc17440eb.pdf.

Edwards, T., 2020. Low Traffic Neighbourhoods: anger, hate and the politics of the planter. BBC News, 17th September. https://www.bbc.co.uk/news/uk-england-lon don-54180647.

Fecht, D., Fischer, P., Fortunato, L., Hoek, G., de Hoogh, K., Marra, M., Kruize, H., Vienneau, D., Beelen, R., Hansell, A., 2015. Associations between air pollution and socioeconomic characteristics, ethnicity and age profile of neighbourhoods in England and the Netherlands. Environ. Pollut. 198, 201-210. https://doi.org/ 10.1016/j.envpol.2014.12.014.

Ferguson, M., Roberts, H.E., McEachan, R.R.C., Dallimer, M., 2018. Contrasting distributions of urban green infrastructure across social and ethno-racial groups. Landscape and Urban Planning 175, 136-148.

Firth, C.L., Baquero, B., Berney, R., Hoerster, K.D., Mooney, S.J., Winters, M., 2021. Not quite a block party: COVID-19 street reallocation programs in Seattle, WA and Vancouver, BC. SSM - Popul. Health 14 (1), 100769. https://doi.org/10.1016/j. ssmph.2021.100769.

Flanagan, E., Lachapelle, U., El-Geneidy, A., 2016. Riding tandem: does cycling infrastructure investment mirror gentrification and privilege in Portland, OR and Chicago, IL? Res. Transp. Econ. 60, 14-24. https://doi.org/10.1016/j. retrec.2016.07.027.

Goodman, A., Urban, S. and Aldred, R., 2020. The impact of Low Traffic Neighbourhoods and other active travel interventions on vehicle ownership: findings from the Outer London Mini-Holland Programme. Findings, December. Doi:10.32866/001c.18200.

Hart, J., Parkhurst, G., 2011. Driven to excess: impacts of motor vehicles on the quality of life of residents of three streets in Bristol UK. World Transp. Policy Pract. 17 (2), $12-30$.

Hirsch, J.A., Green, G.F., Peterson, M., Rodriguez, D.A., Gordon-Larsen, P., 2017. Neighborhood sociodemographics and change in built infrastructure. J. Urbanism: Int. Res. Placemak. Urban Sustain. 10 (2), 181-197. https://doi.org/10.1080/ 17549175.2016.1212914.

Houde, M., Apparicio, P., Séguin, A.-M., 2018. A ride for whom: has cycling network expansion reduced inequities in accessibility in Montreal, Canada? J. Transp. Geogr. 68, 9-21. https://doi.org/10.1016/j.jtrangeo.2018.02.005.

Jacobs, J., Alston, L., Needham, C., Backholer, K., Strugnell, C., Allender, S., Nichols, M., 2019. Variation in the physical activity environment according to area-level socioeconomic position-a systematic review. Obes. Rev. 20 (5), 686-700.

Jephcote, C., Chen, H., Ropkins, K., 2016. Implementation of the polluter-pays principle (PPP) in local transport policy. J. Transp. Geogr. 55, 58-71. https://doi.org/ 10.1016/j.jtrangeo.2016.06.017.

Kenyon, A., Pearce, J., 2019. The socio-spatial distribution of walkable environments in urban Scotland: a case study from Glasgow and Edinburgh. SSM - Popul. Health 9 100461. https://doi.org/10.1016/j.ssmph.2019.100461.

Lee, R.J., Sener, I.N., Jones, S.N., 2017. Understanding the role of equity in active transportation planning in the United States. Transp. Rev. 37, 211-226. https://doi. org /10.1080/01441647.2016.1239660.

Lucas, K., 2012. Transport and social exclusion: where are we now? Transp. Policy, Urban Transport Initiat. 20, 105-113. https://doi.org/10.1016/j. tranpol.2012.01.013.

Lucas, K., Jones, P., 2012. Social impacts and equity issues in transport: an introduction. J. Transp. Geogr. 21, 1-3. https://doi.org/10.1016/j.jtrangeo.2012.01.032.

Lucas, K., Mattioli, G., Verlinghieri, E., Guzman, A., 2016. Transport poverty and its adverse social consequences. Proc. Inst. Civ. Eng. Transp. 169, 353-365. https://doi. org/10.1680/jtran.15.00073.
Macintyre, S., Macdonald, L., Ellaway, A., 2008. Do poorer people have poorer access to local resources and facilities? The distribution of local resources by area deprivation in Glasgow, Scotland. Social Science \& Medicine 67 (6), 900-914.

Mears, M., Brindley, P., Maheswaran, R., Jorgensen, A., 2019. Understanding the socioeconomic equity of publicly accessible greenspace distribution: the example of Sheffield, UK. Geoforum 103, 126-137.

Mitchell, R., Popham, F., 2008. Effect of exposure to natural environment on health inequalities: an observational population study. Lancet 372 (9650), 1655-1660.

Papa, E., Badstuber, N., 2020. Cars: transition from lockdown is a fork in the road - here are two possible outcomes for future travel. Conversation [Online]. [Accessed 16 December 2020]. Available from: http://theconversation.com/cars-transition-fro m-lockdown-is-a-fork-in-the-road-here-are-two-possible-outcomes-for-future-trave 1-139885.

Parra, D.C., Gomez, L.F., Pinzon, J.D., Brownson, R.C., Millett, C., 2018. Equity in cycle lane networks: examination of the distribution of the cycle lane network by socioeconomic index in Bogotá, Colombia. Cities Health 2, 60-68. https://doi.org/ 10.1080/23748834.2018.1507068.

Pistoll, C., Goodman, A., 2014. The link between socioeconomic position, access to cycling infrastructure and cycling participation rates: an ecological study in Melbourne, Australia. J. Transp. Health 1 (4), 251-259.

Rabl, A., de Nazelle, A., 2012. Benefits of shift from car to active transport. Transp. Policy 19, 121-131. https://doi.org/10.1016/j.tranpol.2011.09.008.

Stockton, J.C., Duke-Williams, O., Stamatakis, E., Mindell, J.S., Brunner, E.J., Shelton, N. J., 2016. Development of a novel walkability index for London, United Kingdom: cross-sectional application to the Whitehall II study. BMC Public Health 16 (1), 416.

Su, J.G., Jerrett, M., McConnell, R., Berhane, K., Dunton, G., Shankardass, K., Reynolds, K., Chang, R., Wolch, J., 2013. Factors influencing whether children walk to school. Health Place 22, 153-161.

Teunissen, T., Sarmiento, O., Zuidgeest, M., Brussel, M., 2015. Mapping equality in access: the case of Bogotá's sustainable transportation initiatives. Int. J. Sustain. Transp. 9, 457-467. https://doi.org/10.1080/15568318.2013.808388.

Thornton, C.M., Conway, T.L., Cain, K.L., Gavand, K.A., Saelens, B.E., Frank, L.D., Geremia, C.M., Glanz, K., King, A.C., Sallis, J.F., 2016. Disparities in pedestrian streetscape environments by income and race/ethnicity. SSM - Popul. Health 2, 206-216. https://doi.org/10.1016/j.ssmph.2016.03.004.

Transport for London, 2018. The Mayor's Transport Strategy. TfL, presumably, London:. https://tfl.gov.uk/corporate/about-tfl/the-mayors-transport-strategy

Transport for London, 2019. Liveable Neighbourhoods Programme Guidance. http://co ntent.tfl.gov.uk/tfl-liveable-neighbourhood-guidance.pdf.

Transport for London, 2020. The Strategic Neighbourhood Analysis. http://content.tfl.go v.uk/lsp-app-six-b-strategic-neighbourhoods-analysis-v1.pdf.

Tucker, B., Manaugh, K., 2018. Bicycle equity in Brazil: access to safe cycling routes across neighborhoods in Rio de Janeiro and Curitiba. Int. J. Sustain. Transp. 12, 29-38. https://doi.org/10.1080/15568318.2017.1324585.

Walker, G., Burningham, K., 2011. Flood risk, vulnerability and environmental justice: evidence and evaluation of inequality in a UK context. Crit. Soc. Policy 31, 216-240. https://doi.org/10.1177/0261018310396149ca.

Wheeler, B.W., Lovell, R., Higgins, S.L., White, M.P., Alcock, I., Osborne, N.J., Husk, K., Sabel, C.E., Depledge, M.H., 2015. Beyond greenspace: an ecological study of population general health and indicators of natural environment type and quality. Int. J. Health Geogr. 14 (1), 17.

Woodcock, J., Givoni, M., Morgan, A.S., 2013. Health impact modelling of active travel visions for England and wales using an integrated transport and health impact modelling tool (ITHIM). PLoS One 8 (1), e51462.

Zandieh, R., Flacke, J., Martinez, J., Jones, P., van Maarseveen, M., 2017. Do inequalities in neighborhood walkability drive disparities in older Adults' outdoor walking? Int. J. Environ. Res. Public Health 14 (7). 